\title{
- L ARQUITECTO RAFAEL GUASTAVINO (1842-1908): OBRA EN CUATRO ACTOS
}

\author{
FERNANDO VEGAS LÓPEZ-MANZANARES \\ Universitat Politècnica de València \\ fvegas@cpa.upv.es \\ CAMILLA MILETO \\ Universitat Politècnica de València \\ cami2@cpa.upv.es \\ VÍCTOR MANUEL CANTERO SOLÍS \\ Universitat Politècnica de València \\ victorcanterosolis@gmail.com
}

Resumen: El presente texto desvela numerosos detalles inéditos sobre la figura del arquitecto Rafael Guastavino Moreno (1842-1908) su entorno y sus relaciones personales y familiares con la arquitectura y otras ramas del arte y los oficios como la música y la carpintería, así como con la vitivinicultura. Estas influyeron y retroalimentaron su arquitectura dentro del contexto histórico, político y económico de las tres localidades donde residió en España, a saber, Valencia, Barcelona y Almudévar (Huesca). Más tarde, emigró a los Estados Unidos de América, donde desarrolló una carrera profesional de éxito como arquitecto conocida y difundida por la bibliografía.

Palabras clave: música / carpintería / vitivinicultura / arquitectura / clientes.

Abstract: This text presents extensive new information on the figure of architect Rafael Guastavino Moreno (1842-1908), those around him, and his personal and family relationships with architecture. It also examines other artistic fields and trades such as music, carpentry and winemaking, all of which influenced and obtained feedback for Guastavino's architecture within the historical, political and economic situation of the three places where he lived in Spain: Valencia, Barcelona and Almudévar (Huesca), before emigrating to the United States of America, where his successful professional career as an architect is widely recognized in the literature.

Key words: music / carpentry / winemaking / architecture / customers.

\section{Obertura}

El arquitecto Rafael Guastavino Moreno (18421908), una figura fundamental para entender los prolegómenos del Modernismo arquitectónico en Barcelona y la conformación de la arquitectura pública en la Costa Este de los Estados Unidos, ha sido rescatado del olvido en las últimas décadas. El principal mérito corresponde al Prof. George
Collins, de la Columbia University, que literalmente recuperó de la basura los archivos de la empresa en 1962 y publicó una primera aproximación en 1968. ${ }^{1}$ A partir de este primer artículo, cabe destacar, entre otras, las sucesivas aportaciones realizadas por Jaume Rosell Colomina; ${ }^{2}$ el catálogo de la exposición comisariada por Javier García-Gutiérrez Mosteiro ${ }^{3}$ que reunía todo el conocimiento del arquitecto hasta la fecha; el libro y el catálogo

* Fecha de recepción: 15 de abril de 2017 / Fecha de aceptación: 14 de septiembre de 2017.

1 COLLINS, George. "The transfer of thin masonry vaulting from Spain to America". Journal of the Society of architectural Historians, 1968, Vol. 27, No. 3, Oct., pp. 176-201, doi: 10.2307/988501.

2 ROSELL COLOMINA, J. "Rafael Guastavino i Moreno: enginy en I'arquitectura del segle XIX". En: Ciència i Tècnica als Països Catalans: una aproximació biogràfica. Barcelona: Fundació Catalana per la recerca, 1995.

3 HUERTA, Santiago (ed.). Las bóvedas de Guastavino en América. Madrid: Instituto Juan de Herrera, 2001. 
de la exposición comisariada por Mar Loren, ${ }^{4}$ que difundía la trascendencia de su obra entre el gran público; los artículos de algunos de los autores de este texto, ${ }^{5}$ que profundizaban en el contexto y revelaban las raíces familiares de la obra de Guastavino; y la monografía publicada por John Ochsendorf, ${ }^{6}$ estupendamente ilustrada por fotografías de Michael Freeman.

Sin embargo, existen todavía numerosas lagunas en torno a su vida en España y sus relaciones personales, familiares y profesionales durante los primeros 39 años de su vida que residió en España en tres localidades: Valencia (1842-1859), Barcelona (1859-1881) y, alternando con su domicilio en Barcelona, Almudévar (Huesca) (a partir de 1872), ${ }^{7}$ donde desarrolló sus múltiples facetas. Este tejido de vínculos artísticos, económicos y profesionales brinda claves que permiten contextualizar mejor su obra arquitectónica tanto en España como en ultramar.

Rafael Guastavino Moreno nació en Valencia el 1 de marzo de 1842, en su domicilio de la calle Puñalería número 11, y fue bautizado al día siguiente en la Parroquia de San Pedro de la Catedral Metropolitana de Valencia, ${ }^{8}$ en el seno de una familia paterna vinculada profesionalmente a la música y a la carpintería y una familia materna con una larga tradición relacionada con la arquitectura en el entorno vitivinícola de las comarcas del Bajo Aragón. Estos cuatro polos, música, carpintería, producción vitivinícola y arquitectura, marcarán el desarrollo posterior de su vida. ${ }^{9}$

\section{Primer acto: La música}

Tanto los textos autógrafos como los relatos biográficos de Rafael Guastavino están salpicados de alusiones a la música, que constituye un referente constante durante toda su vida. Se sabe que Rafael Guastavino había recibido clases formales y tocaba el violín en su juventud, hasta el punto que en un principio quiso ser intérprete profesional. ${ }^{10}$ Guastavino descartó esta opción por la arquitectura cuando descubrió la obra de su tatarabuelo Juan José Nadal (1690-1763), ${ }^{11}$ pero seguiría tocando el violín durante el resto de su vida como afición personal, ${ }^{12}$ incluso al final de sus días en su casa de Black Mountain (Carolina del Norte, EUA), donde componía música propia y amenizaba a sus invitados. ${ }^{13}$ La trascendencia de este instrumento musical se pone de manifiesto cuando durante la crisis económica de Nueva York de 1883 y 1884, ${ }^{14}$ se vio incluso obligado a empeñar su violín, que él consideraba su bien más preciado, una verdadera tragedia personal que trascendió en el tiempo hasta haber quedado reflejada en nuestros días. ${ }^{15}$

${ }^{4}$ LOREN MÉNDEZ, M. Mar. Texturas y Pliegues de una nación. New York City: Guastavino Co. y la reinvención del espacio público de la metrópolis. Valencia: TC Ediciones 2008.

5 VEGAS, Fernando. "Los orígenes valencianos en la obra de Guastavino". En: HUERTA, Santiago (ed.), 2001, pp. 253-270; VEGAS, Fernando; MILETO, Camilla. "Rafael Guastavino: una historia de la arquitectura entre bambalinas". Loggia, Arquitectura \& Restauración n² 20, 2007, pp. 24-27; VEGAS, Fernando; MILETO, Camilla. "Consistencia de las raíces valencianas en la obra de Guastavino". En: LOREN MÉNDEZ, M. Mar (ed.). Guastavino Co. La reinvenció de l'espai públic a New York. Valencia: Generalitat Valenciana, 2008, pp. 31-39; VEGAS, Fernando; MILETO, Camilla. "Guastavino y el eslabón perdido." Construyendo bóvedas tabicadas: actas del Simposio Internacional sobre bóvedas tabicadas. Valencia: Editorial Universitat Politècnica de València, 2012.

${ }^{6}$ OCHSENDORF, John Allen. Guastavino vaulting. The art of structural tile. Princeton Architectural Press, 2014; publicado también en castellano en OCHSENDORF, John Allen. Las bóvedas de Guastavino: el arte de la rasilla estructural. Barcelona: Papersdoc, Ajuntament de Barcelona, 2014.

7 OLIVA i RICÓS, Benet, 2009

${ }^{8}$ AGMS, 1a , 4065G, Exp. 02. Copia de la partida bautismal de Rafael Guastavino Moreno realizada el 6 de agosto de 1850 del folio 140 del Libro de bautismos que comienza en 1835 de la Catedral de Valencia, adjunta a la Hoja de Servicios de su hermano José Guastavino Moreno, militar castrense.

${ }^{9}$ A estos cuatro polos habría que añadir también los de empresario constructor y fabricante cerámico, que, de una u otra manera vamos a asimilar en el panorama de este artículo en el ámbito de la arquitectura, por simplificar el discurso.

10 GUASTAVINO IV, R., 2006, p. 1. Es muy probable que esas lecciones a las que se refiere su nieto las recibiera el futuro arquitecto en su propia casa de parte de alguno de sus familiares ya mencionados. Wight afirma que fue educado como músico y apunta la fácil transición entre la profesión de músico y arquitecto, como sucedía también con los arquitectos de antaño Jacob Wray Mould y John Wellborn Root. Véase: WIGHT, Peter B. "The Works of Rafael Guastavino. Part I-As Architect". The Brickbuilder, April, 1901, p. 79.

11 VEGAS, Fernando; MILETO, Camilla, 2012, p. 148.

12 ROSELL, Jaume, 1995, reeditado en: HUERTA, Santiago (ed.), 2001, p. 201.

13 OCHSENDORF, John Allen, 2014, p. 114.

14 Esta crisis es comúnmente denominada "Pánico financiero de 1884 ".

15 GUASTAVINO IV, R., 2006, pp. 16-17. 
En algunos escritos, Rafael Guastavino comparaba la arquitectura y la música, ambas artes necesitadas no solo del creador, sino también del ejecutante: "En arquitectura, lo mismo que en el arte musical, es más necesario que en escultura ó en pintura, crear por grados los elementos indispensables, porque en estas últimas el artista es por sí mismo el ejecutor directo, mientras que en música ó arquitectura tiene necesidad de ejecutantes que sean el medio á favor del cual pueda presentar sus ideas al público". Además, comparaba la instrucción musical con la enseñanza de la arquitectura, por su doble carácter teórico y práctico: "Es evidentemente necesario que los jóvenes arquitectos se hallen en íntimo contacto con todos esos elementos por un sistema de estudio semejante al seguido en las academias de música; es decir, estudiando la teoría y la práctica bajo la dirección de la academia...". ${ }^{16}$

Pero, ¿de dónde procedía la melomanía del arquitecto Rafael Guastavino? En textos anteriores, ${ }^{17}$ se ha apuntado la tradición musical de Valencia con el surgimiento de las bandas de música municipales a partir de la Milicia Nacional durante el siglo XIX y la profesión de constructor de pianos de su abuelo paterno, pero sin descartar la influencia de la primera, la segunda hipótesis cobra extraordinaria fuerza a raíz de nuevos datos sobre su entorno familiar.

En efecto, el abuelo paterno de Rafael Guastavino, Davide Giuseppe Guastavino (1780-¿1833?) -en adelante David José Guastavino- había venido a España procedente de Varazze (Liguria) en 1798 y era constructor de pianos. ${ }^{18}$ Nuevos datos extraídos de su partida matrimonial ${ }^{19}$ hasta ahora desconocidos, nos informan que también era profesor de música. Además, David J. Guastavino oficiaba como templador de claves y pianos, mientras residía en la ciudad de Barcelona en la calle de Arolas, casa Roses, tercer piso. ${ }^{20}$ Oriol Brugarolas añade que es la primera referencia que existe sobre alguien dedicado de forma simultánea a la tarea de afinador y comerciante de pianos. Al hilo de la Guerra del Francés (1808-1814) residió en Palma de Mallorca, ${ }^{21}$ y de nuevo volvió a Barcelona, donde estuvo como máximo hasta 1825,22 cuando estaba viviendo ya en Valencia. Alrededor de una década vivió David Guastavino en la ciudad del Turia y, poco o nada se conoce acerca de su actividad musical o profesional durante este tiempo.

Para tratar de comprender el entorno en el que pudo desenvolverse David José Guastavino, se ha esbozado el contexto de la manufactura de pianos y su vinculación a la carpintería en el cambio del siglo XVIII al XIX en España. Fue en la última década del siglo XVIII, principalmente en Barcelona y Madrid, cuando desde la emergente burguesía se empieza a valorar el piano, dando lugar a un incremento notable en la actividad comercial relacionada con su manufactura y compraventa. Se conocen en este periodo, al menos cuatro talleres de constructores de pianos en Barcelona y ocho en Madrid. Después de la Guerra del Francés, aumentó considerablemente la manufactura de pianos en el país llegando a existir catorce ta-

${ }^{16}$ GUASTAVINO MORENO, Rafael, 1895, pp. 11-12.

17 Véanse: VEGAS, Fernando. "Los orígenes valencianos en la obra de Guastavino". En: HUERTA, Santiago. Las bóvedas de Guastavino en América. Madrid: Instituto Juan de Herrera, 2001, pp. 253-270; y VEGAS, Fernando; MILETO, Camilla. "Consistencia de las raíces valencianas en la obra de Guastavino". En: LOREN MÉNDEZ, M. Mar. Guastavino Co. La reinvenció de l'espai públic a New York. Valencia: Generalitat Valenciana, 2008, pp. 31-39.

18 MILETO, Camilla; VEGAS, Fernando, 2012, p. 134

19 ADB. Parròquies, Santa María del Pi, microfilms, Matrimoni 1806 D.J. Guastavino-A. Buch. Se casó con Antonia Buch Martínez el 21 de enero de 1806 en la parroquia de Santa María del Pi. En el momento de la celebración su madre Jacinta Stagnari seguía con vida, pero no se ha podido precisar si en Barcelona o en su lugar de origen.

20 Diario de Barcelona, 8-XII-1806; DdB, 15-II-1807. Citado por BRUGAROLAS, Oriol, 2015, p. 212.

21 BRUGAROLAS, Oriol, 2015, p. 166. Hay constancia documental de muchos artesanos que trasladaron sus talleres a Palma durante la ocupación francesa de Barcelona o simplemente los cerraron, situación que afectaría sin duda a David. Durante su estancia en Mallorca nació su primogénito Antonio Guastavino Buch el 20 de febrero de 1810. Dato extraído de Pierre-Marie Guastavino titulado Les Guastavino: une famillie Gênoise et d'Oltreioso. Archivo privado de Carlos Donderis Guastavino, Valencia. Estudio inédito de la genealogía de la familia Guastavino.

22 Este año nació en Valencia Dolores Guastavino Buch y también lo harían José (1828) y Salvadora (1833). El primer registro donde se encuentra a David Guastavino (a partir de ahora registrado indistintamente bajo los nombres de José o David) en Valencia, es el libro de matrícula pastoral de la parroquia de San Esteban Protomártir de 1831. Vive en la calle de las Nieves número veintisiete junto a su mujer y sus siete hijos. En el libro de matrícula pastoral de 1833 José ya no está y su mujer era ya viuda. Faltaba por nacer Salvadora que lo haría en torno al 22 de agosto de 1833, siendo esta la fecha de su defunción. En el libro de índice de defunciones de la parroquia de San Esteban, se la inscribe como albat, es decir que murió al poco tiempo de nacer. 
lleres en la ciudad condal y quince en la capital. ${ }^{23}$ Sin embargo, hubo que esperar hasta 1830 para encontrar el primer taller de construcción de pianos importante en Valencia. ${ }^{24}$ De los talleres existentes en las tres ciudades hasta 1830, ninguno perteneció, al menos oficialmente, a David José Guastavino, lo que puede apuntar a que simplemente fuera empleado en alguno de ellos o algo más difícil en la época, que trabajase de forma autónoma. ${ }^{25}$

Se tienen otras dos noticias sobre David Guastavino correspondientes a sus últimos años de vida, que unidas a las de sus primeros años en Barcelona, pueden ayudarnos a trazar una trayectoria profesional dedicada exclusivamente a la música, eso sí, con más sombras que luces. Sobre su actividad profesional en Madrid, Martínez Molés nombra un individuo Ilamado José Guastamino, factor de pianos, que en septiembre de 1831 recibe un pago de 120 reales por "la composición del piano de cola del Colegio". ${ }^{26}$ La segunda referencia procede del Diario de Avisos de Madrid, y reza de David José Guastavino lo siguiente: "Se vende o permuta por casas o tierras en Valencia una hermosa casa en Miraflores [...] dará razón el pianista y afinador D. David Guastavino, calle del Fúcar, número 7, cuarto bajo de la izquierda".27

En aquellos años dirigía la Real Capilla de música del Colegio de Niños Cantores el maestro Francis- co Andreví. ${ }^{28}$ Llama la atención el paralelismo que existe entre la trayectoria del maestro Andreví y la de David José Guastavino. Al finalizar la Guerra del Francés, ambos son vecinos de Barcelona y se dedican a la música. En la década de 1820, Andreví es maestro de capilla de la Catedral de Valencia y se sabe que hacia 1825 José Guastavino vive también en Valencia. En 1831, un año después de que Andreví haya ganado la oposición para el Colegio de la Real Capilla en Madrid, Guastavino realiza la composición del piano de la misma. A primera vista, puede llamar la atención el orden y los destinos que ambos músicos tuvieron. Se podría pensar que Guastavino iba siguiendo la estela de Andreví, pero resultaría muy arriesgado afirmar tal cosa. No se puede asegurar que ambos músicos se conocieran personalmente desde su estancia en Barcelona; sin embargo, lo que sí está claro es que se movían en el mismo círculo profesional, la música. No existe un expediente personal de David José Guastavino en la sección de personal del Archivo General de Palacio. No obstante, esta ausencia documental puede reforzar la hipótesis de que el maestro de Sanahuja y el de Varazze pudieran conocerse. De no ser así, ¿cómo se justifica que Guastavino realizase aquel trabajo de composición y afinación del piano de la Real Capilla con su residencia oficial en Valencia anteponiéndose a los oficialmente destinados a tal menester? ${ }^{29}$

23 BRUGAROLAS, Oriol, 2015, p. 158.

${ }^{24}$ ALEMANY, Victoria, 2007, p. 342. Este taller fue el de Pedro Gómez, fundado en 1830. Pedro Gómez nació en Teruel en 1812 y antes de llegar a Valencia pasó por Barcelona donde fue aprendiz del taller de órganos Font y de aquí pasó a Madrid a trabajar en el de los holandeses Juan y Pedro Hazen Hosseschrueders.

25 Lo habitual era que los constructores de pianos estuvieran agremiados junto a los carpinteros, por ser la madera su materia prima de trabajo. De esta forma tenían fácil acceso al material y además se evitaban pleitos con el gremio y otros maestros, pues no les estaba permitido abrir taller propio sin estar agremiados.

${ }^{26}$ MARTíNEZ MOLÉS, Vicente, 2015, p. 219. Se da con frecuencia en numerosos documentos consultados, el error ortográfico en la anotación del apellido Guastavino, así, se ha encontrado como "Gustavino", "Guartavino", "Guastavinos" e incluso como en esta ocasión, "Guastamino". Según se desprende del estudio inédito sobre la familia Guastavino realizado por Pierre Guastavino, el músico genovés fue el primero de su estirpe en pisar territorio español, por lo que, la errata en el apellido no descarta en absoluto que se trate de nuestro David José Guastavino. Véase también: ASENJO BARBIERI, Francisco. Documentos sobre música española y epistolario (Legado Barbieri), n 381, vol. 2, Ed. de Emilio Casares. Madrid: Fundación Banco Exterior, 1988, p. 196. Esta referencia ha sido facilitada por la Dra. Cristina Julia Bordas Ibáñez de la Universidad Complutense de Madrid. El documento original se encuentra en la Biblioteca Nacional de España, sección de manuscritos, Papeles Barbieri, signatura MSS 14.073 (13)

27 Diario de Avisos de Madrid, 31-XII-1831. Más allá de conocer si la casa en venta era de su propiedad o él era el mero intermediario, esta noticia interesa por cuanto informa de su profesión.

${ }^{28}$ Francisco Andreví nació en Sanahuja (Lérida) en 1786. Ocupó el puesto de maestro de capilla de la catedral de Segorbe hasta 1814, cuando ganó por oposición el mismo puesto en la parroquia barcelonesa de Santa María del Mar. De allí pasó en 1819 a la Catedral de Valencia donde permaneció durante diez años. Tras un fugaz paso por la Catedral de Sevilla, ganó en 1830 el puesto de maestro de la Real Capilla del Palacio Nuevo de Madrid, hasta que en 1836 emigró a Burdeos y París. Véase: MARTíNEZ, Vicente, 2015.

29 Los afinadores de la Real Capilla en 1831 eran Jorge Bosch y Juan Vergara que recibían un sueldo mensual de 50 reales por trabajos de mantenimiento de los instrumentos. Tampoco ha sido posible localizar hasta el momento dato alguno sobre David José Guastavino en el RCMM. Si a esto se une su presencia en los libros de recuento pastoral de la parroquia de San Esteban de Valencia entre 1831 y 1833 ambos inclusive, y que la última hija nacida de su matrimonio con Antonia Buch falleció en 
El único dato fehaciente sobre su fallecimiento es el que consta en la partida bautismal de su nieto Rafael Guastavino Moreno, donde se menciona que David Guastavino natural de Génova, había fallecido en Madrid. ${ }^{30}$

La trascendencia artística y musical del italiano David José Guastavino sería notable. Su primogénito Antonio Guastavino Buch (1810-1876) fue pianista y así ejerció a lo largo de su estancia en Valencia hasta su muerte. ${ }^{31}$ A su vez, el primogénito de éste y primo hermano de nuestro arquitecto, Antonio Guastavino Escribá (1837-¿1897?), fue también afinador de pianos ${ }^{32}$ dando así continuidad a la profesión de su abuelo, maestría que debió recibir a través de su padre Antonio Guastavino Buch. Es de suponer el contacto entre las familias Guastavino-Escribá y Guastavino-Buch en la década de los cuarenta y cincuenta del ochocien- tos y, tampoco sería de extrañar, que en alguno de sus domicilios hubiera algún piano, quién sabe si construido por ellos mismos, con el que amenizaran sus reuniones familiares, y de esta manera, despertaran el interés musical en alguno de los benjamines de la familia.

Así pudo suceder también con Antonio Guastavino Moreno (1837-1919), hermano mayor del arquitecto Rafael, que era ya músico en $1855 .{ }^{33}$ Pocos años después, hacia 1859 desaparece su rastro, y vuelve a aparecer entre septiembre de 1863 y marzo de 1864, matriculado en el Real Conservatorio de Música de Madrid. ${ }^{34}$ Su puesto más relevante fue el de maestro de capilla de música en la Catedral de Santiago de Cuba, plaza que ocupó entre 1869 y 1875.35 Durante toda su carrera compuso notables obras, mayormente para piano y voz, dos de las cuales se encuentran

agosto de 1833, todo parece indicar que su vinculación con Madrid fue algo puntual o como mucho esporádica. De esta forma podría entenderse que cobrara el doble de la cantidad que recibían mensualmente los afinadores oficiales de la Real Capilla. Faltaría conocer en todo este asunto qué es lo que le hacía seguir en Madrid hacia 1833, donde finalmente expiró. ¿Quizás su contacto con Andreví, ahora sí evidente, le proporcionaba algún trabajo concreto que conseguía por su recomendación y esto le hacía ir y venir de Valencia a Madrid?

30 El documento está fechado el dos de marzo de 1842 y acerca del fallecimiento de su abuelo dice que tuvo lugar en la parroquia de San Sebastián de Madrid pero sin especificar la fecha. Desafortunadamente no ha sido posible encontrar la partida de defunción en el archivo de dicha parroquia ni tampoco en el Archivo Histórico Diocesano de Madrid. Sin embargo, el hecho de que su hija Salvadora muriera recién nacida en agosto de 1833, sitúa la muerte de José Guastavino a partir del inicio de este año 1833.

${ }^{31}$ Antonio Guastavino Buch falleció en su casa de la calle Trinitarios número ocho, piso tercero de la izquierda el 23 de enero de 1876, como así consta en su certificado de defunción conservado en la Sección $3^{\text {a }}$ del Tomo 28-2, folio 113, número 112 del Registro Civil de Valencia.

32 Antonio Guastavino Escribá nació en Valencia en el 1837. Se casó con Carolina Robba Medina, nacida en el seno de una familia de artesanos diamantistas residentes en la plaza de las Barcas nº 4 (AHMV, Padrón General, año 1837, Legajo 8bis, Distrito Mar, Barrio 2). Una vez casados Antonio y Carolina vivieron en el domicilio familiar de los Robba hasta que en 1897 Carolina es viuda y vive en la localidad de Sueca, plaza del Vall, $n^{\circ} 50$. Datos obtenidos de la web www.familysearch.com (fecha de consulta: 30-III-2017).

33 AHMV, Padrón General, Año 1855, Legajo 86, Cuartel del Mercado, Barrio 3. Antonio había estado ausente del domicilio familiar entre 1845 y 1852. Se ha podido encontrar su nombre en el libro de inscripciones de infantillos del Real Colegio Seminario del Corpus Christi de Valencia (ARCSCC. Histórico-Capilla-Personal-Elecciones-144 "Asientos de los infantillos y moços de coro y otras personas"). En estos siete años combinaría estudios de teología y música, disciplinas que marcaron sin duda el resto de su vida. Para más información sobre Antonio Guastavino Moreno véase: CONRADO, Ángel. Religiosos ilustres de las seráficas provincias de valencia. Valencia: Editorial Revista Apóstol y Civilizador, 1988. Contiene una biografía generosa en datos, pero en la que no se abundará. Además incluye una relación de obras musicales compuestas por Antonio, en Madrid, Cuba y Valencia, que dan muestra de su categoría musical.

${ }^{34}$ Archivo del RCSMM, L-151. Índice alfabético de Alumnos Matriculados (1839-1900). Su número de matrícula fue 3421; L-145 Índice Numérico de Alumnos (1859-1868). Consta que se matriculó de Armonía en 1863, dándose de baja voluntariamente en 1864; L-082 Registro de Pagos al Estado por Derechos de Matrícula y Examen. Enseñanza Oficial (1863-1864). Sólo pago el primer plazo; L-216. Libro de Clases. Se matriculó en la clase del profesor Rafael Hernando pero se dio de baja en marzo de 1864.

35 HERNÁNDEZ BALAGUER, Pablo, 1964, p. 47. Según otro artículo, FLEITAS, Ma Teresa. "Santiago de Cuba: la modernización postergada". En: Estudios de historia social y económica de América, ISSN 0214-2236, № 12, 1995, pp. 141-164, Antonio ya se encontraba en Santiago de Cuba en 1868. Sin embargo, en los primeros meses de 1869, Antonio solicita al Ayuntamiento de Valencia un permiso para establecer una academia de música donde impartir clases. AHMV, Sec. Fomento-Instrucción Pública, $3^{a} \mathrm{G}, I I{ }^{a} B$ (1865-1895). A tenor de lo expuesto, parece ser que durante el tiempo transcurrido desde que ganara la plaza de maestro de Capilla para Santiago de Cuba hasta que la ocupó definitivamente, realizó con toda probabilidad algún viaje más entre la Península y la Isla de Cuba. Que se haya podido confirmar, es el que zarpó de Cádiz el 20 de junio de 1871 con destino a La Habana. Así lo demuestra un dato obtenido de la web http://www.cubagenweb.org/ships/e-index.htm (Fecha de consulta: 27-III-2017). Los datos de barcos y pasajeros que llegaban a Cuba desde la Península y que están reflejados en dicha página web, fueron tomados de dos periódicos de la época que son el Diario de la Marina y la Gaceta de la Habana. 


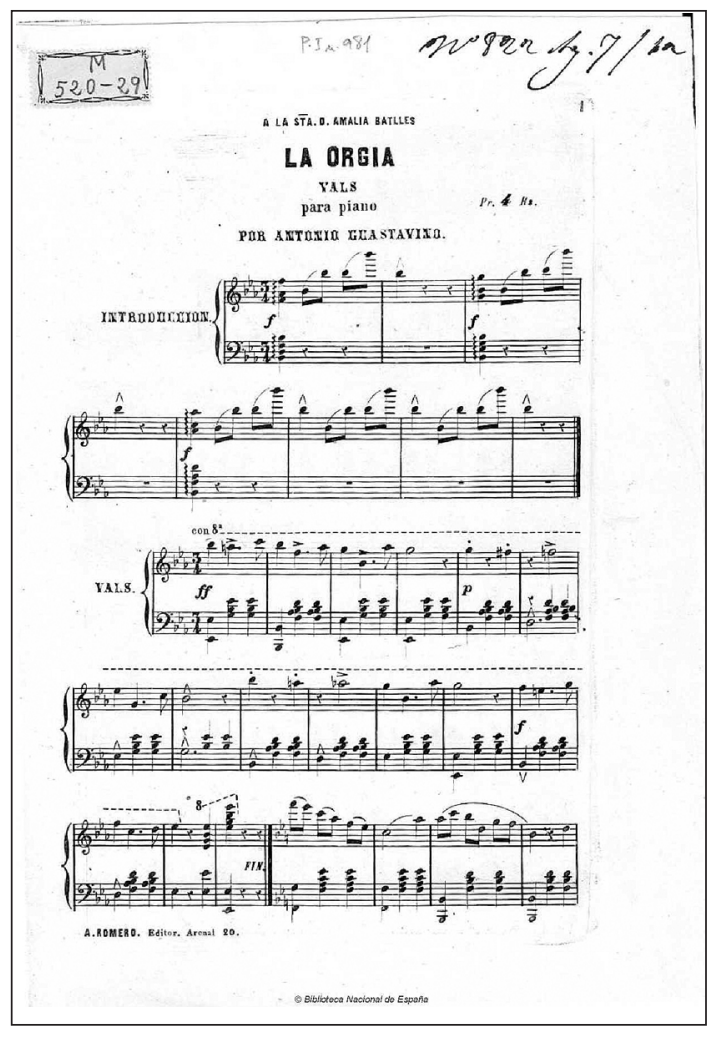

Fig. 1. La Orgía. Vals para piano en Mi bemol mayor. Antonio Guastavino Moreno, 1862. BNE. Sede Recoletos, $\mathrm{MC} / 520 / 29$.

en la $\mathrm{BNE}^{36}$ (Fig. 1). Con toda probabilidad sea Antonio el músico más reconocido que haya dado la familia Guastavino, con permiso del también pariente lejano, músico y pianista argentino Carlos Vicente Guastavino (1912-2000). ${ }^{37}$

Por otra parte, la sensibilidad musical del arquitecto Rafael Guastavino Moreno le sirvió para detectar que muchas de sus cúpulas tenían importantes problemas de reverberación y concentración del sonido en partes determinadas del espacio inferior, de modo que todavía en vida intentó solucionar estos problemas con la patente 464.563
Cohesive Ceiling Floor ${ }^{38}$ para mejorar las condiciones acústicas de sus materiales. Sin embargo, fue su hijo quien aportaría las soluciones más conocidas en el campo de la acústica arquitectónica.

No se poseen datos sobre una posible afición paralela a la música de su hijo Rafael Guastavino Expósito (1872-1950). Su llegada a los Estados Unidos con 8 años de edad, su educación inicial en un internado, y su temprana incorporación a la profesión de su padre, con apenas 15 años de edad, ${ }^{39}$ probablemente le restó las oportunidades que tuvo su padre en su entorno familiar de aprender a interpretar un instrumento. Sin embargo, trazas de esa sensibilidad por la música de la tradición familiar se pueden rastrear en su vocación para la creación de espacios acústicamente adecuados, con la creación de las patentes de la plaqueta acústica Rumford y el ladrillo Akoustolith, ${ }^{40}$ pensadas para mejorar las condiciones acústicas de sus edificios, diseñadas junto a Wallace $C$. Sabine (1868-1919), uno de los pioneros de la ciencia de la acústica arquitectónica. ${ }^{41}$ En el fondo, de forma muy similar a su bisabuelo David José Guastavino, Rafael Guastavino Expósito también diseñaba y construía cajas de resonancia para la música, el primero en forma de pianos y el segundo en forma de espacios arquitectónicos abovedados.

\section{Segundo acto: La carpintería}

Por una cuestión de evidente afinidad, los constructores de pianos de antaño y los carpinteros podían, e incluso debían pertenecer al mismo gremio. De esta forma ha quedado reflejado en el punto anterior, en relación a la figura de David José Guastavino. Mucho más esclarecedora es la labor profesional del hijo de éste, Rafael Guastavino Buch, a su vez padre del arquitecto Rafael Guastavino Moreno. Numerosas son las referencias que afirman su ocupación como ebanista, comenzando por su colaboración en la manufactura de las puertas de la Catedral de la Seu d'Urgell

\footnotetext{
36 BNE. Sede Recoletos. Signaturas MP/5176/31 y MC/520/29. La Orgía (Fig. 1) Vals para piano en Mi bemol mayor; MMICRO/4746(32).Quejas, Polka-mazurka recitada, publicados en 1862, el primero por el editor A. Romero y el segundo por los hermanos Carrafa y Sanz.

${ }^{37}$ Nació en Santa Fe (Argentina) el 5 de abril de 1912 en el seno de una familia de financieros. Su filiación es posible reconstruirla gracias al estudio inédito de Jean-Pierre Guastavino ya mencionado anteriormente. Es posible que su bisabuelo Bernardo Guastavino nacido en Varazze fuera hermano de David José Guastavino. Fue abuelo del pianista argentino Paolo Guastavino (1830-1890) nacido también en Varazze, el que emigró a Argentina en 1848 después de un periplo de tres meses. Para conocer más sobre la vida y obra del pianista Carlos Guastavino véase: BULMBERG, Edgardo, 2008, pp. 1-32.

38 LOREN MÉNDEZ, M. Mar, 20, 2007, p. 37.

${ }^{39}$ GUASTAVINO IV, R., 2006, p. ix, 14 y 19, respectivamente.

40 REDONDO MARTÍNEZ, Esther, 2000, pp. 895-905.

${ }^{41}$ OCHSENDORF, John Allen, 2014, pp. 132-134.
} 
en torno a $1834 .{ }^{42}$ Además, hasta la fecha, se conocía en parte su trabajo a través de dos expedientes de obra depositados en el AHMV fechados en 1858 y 1859. ${ }^{43}$ Nuevos descubrimientos demuestran que Rafael Guastavino Buch perteneció al Gremio de Carpinteros de Valencia al menos desde 1859, ${ }^{44}$ donde figura como vocal de la Junta General del Gremio de 26 de febrero de ese año, en la redacción de los estatutos para la fundación de una escuela gratuita de carpintería para jóvenes aprendices. ${ }^{45}$ Rafael Guastavino Buch llegó a ostentar la posición de veedor en el gremio, cargo cuya renovación rechazó el 26 de septiembre de 1869 con las siguientes palabras dirigidas a la Junta General: "hizo presente su agradecimiento por esta prueba de confianza, pero declinaba la honra de continuar ejerciendo su cargo, pues sus muchas ocupaciones le privaban de ello". ${ }^{46}$ En la misma junta se leyó una exposición de sus hijos Carlos $^{47}$ (1851- ¿191015 ?) y Manuel ${ }^{48}$ (1849-¿?) Guastavino Moreno, a la sazón jóvenes maestros del gremio "en la cual manifestaban a la Junta General que ayudados por su padre Don Rafael Guastavino, habían tenido el honor de construir el pasamano a la Castellana de la escalera de la Casa-Gremio". ${ }^{49}$
Se ha mencionado en el pasado ${ }^{50}$ la alta probabilidad de que Rafael Guastavino Buch tuviera su propio taller de carpintería en su domicilio, primero en la calle Puñalería 11 y a partir de 1845 , en la calle Verónica. Se puede constatar dicha existencia gracias a la presencia en el domicilio de varios aprendices de carpintería, además de sus propios hijos. ${ }^{51}$

En cuanto a Rafael Guastavino Moreno, no hay constancia documental en Valencia de una labor profesional dedicada a la carpintería más allá de los datos obtenidos del padrón general de habitantes de Valencia entre 1842 y $1858,{ }^{52}$ en los que se le inscribe como carpintero, del mismo modo que a su padre y sus hermanos. En 1859 no se encuentra en el domicilio familiar y aparece viviendo en solitario en el bajo de la calle Verónica 7, registrado como estudiante y con sirvienta propia. ${ }^{53}$ ¿A qué se debe su emancipación? Además de estudiante, ¿habría conseguido algún trabajo que le permitiera poder costearse el alquiler del bajo contiguo a la casa de sus padres? ¿Sería ese famoso trabajo en un estudio de arquitectura de la época del que habló ya en 1901 Wight? ${ }^{54}$ Resolver

42 GUASTAVINO IV, R., 2006, p. 1

43 MILETO, Camilla; VEGAS, Fernando, 2012, p. 135.

${ }^{44}$ ARV, Gremios. Caja 658, núm. 1202. El expediente indica que en enero de este año, se produjo por parte del arquitecto Juan Fornés un insulto hacia el gremio, motivo por el que "se le confieren amplios poderes al síndico Rafael Guastavino, uno de los Maestros del referido gremio para que lleve a término la reparación de dicho insulto".

45 ARV, Gremios, Caja 658, núm. 1201.

${ }^{46}$ ARV, Gremios, Caja 625, núm. 562.

47 Carlos nació el 26 de julio de 1851. Una vez pasado el año 1870 (AHMV, Padrón general, año 1870, Legajo 151, Distrito Mercado, Barrio 3), la casa familiar de la calle Verónica número 9 es ocupada por otra familia y el bajo es destinado a almacén de molduras (AHMV, Padrón general, año 1873, Legajo 187, Distrito Mercado, Barrio 3), los hermanos de Rafael que continuaban en Valencia en el último registro se dispersan. Éstos eran Vicente, Carlos, Juana que jugaría un importante papel en el futuro del arquitecto, y Manuel. Carlos desaparece y no ha sido posible encontrarle de nuevo hasta 1889, que vive en la calle Llop número 12, piso $2^{\circ}$ (AHMV, Padrón general, año 1889, Legajo 657, Distrito Teatro, Barrio 1, $n^{\circ} 16.685$ ). Hacía apenas un año que había llegado procedente de Marsella, con su mujer Fanny Boyer y sus tres hijos María Luisa y José Guastavino Pecenot, fruto de una primera mujer llamada Jeanne-Marie Pecenot. El dos de diciembre de 1888 nació la tercera y última hija de Carlos, fruto de su matrimonio con Fanny, llamada Carlota Guastavino Boyer. Por ahora, no se conoce nada más de Carlos en cuanto a su profesión como carpintero se refiere, si bien, desde 1889 en el padrón de habitantes de Valencia consta como Comerciante (AHMV, Padrón general, año 1894, Distrito Mercado, Barrio 1, n² 21) y Profesor (AHMV, Padrón general, año 1899, Distrito Universidad, Barrio 4, $n^{\circ}$ 12.067). En 1915, Fanny ya es viuda y ha resultado imposible hasta la fecha encontrar la fecha y lugar de defunción de Carlos (AHMV, Padrón general, año 1915, Legajo Universidad 3, Barrio 4, n 12.263). Es también una incógnita lo que ocurre con Carlos en el transcurso de tiempo entre 1870 y 1889, qué le hace trasladarse y vivir en MarseIla. Sobre Manuel, no se conoce nada más que la noticia que se mencionó anteriormente de su trabajo en el pasamano de la escalera de la Casa del Gremio de Carpinteros de Valencia.

${ }^{48}$ AHMV, Registro de nacidos, Película 1179, n 1230. Manuel nació el 4-V-1849.

${ }^{49}$ ARV, Gremios, Caja 625, núm. 562. Actualmente desaparecido. Se acometió una total remodelación de la Casa Gremio de Carpinteros de Valencia a finales de la década de los noventa del siglo XX.

50 MILETO, Camilla; VEGAS, Fernando, 2012, p. 135

51 AHMV, Padrón General, Años 1855-1857, 1861-1863, Legajos 86, 90, 94 y 106, 110 y 114 respectivamente, Cuartel del Mercado, Barrio 3. El primero de los aprendices es Joaquín Galindo y Sanjuan natural de Valencia, y el segundo es Celestino Muñoz y Pérez de la villa de San Clemente.

52 AHMV, Padrón General, Años 1842-44 y 1845-58, Cuartel del Mercado, Barrio 3.

53 AHMV, Padrón General, Año 1859, Legajo 102, Cuartel del Mercado, Barrio 3.

${ }^{54}$ WIGHT, Peter B. "The Works of Rafael Guastavino. Part I-As Architect". The Brickbuilder, April, 1901, p. 79. 


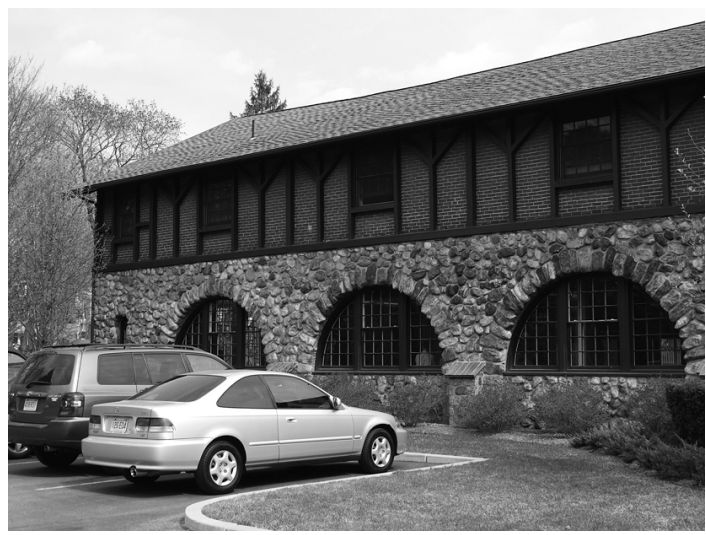

Fig. 2. Antigua fábrica cerámica de los Guastavino en Woburn, Massachussetts. Foto: Vegas \& Mileto.

estas cuestiones resultaría de gran interés para poder finalmente poner nombre y apellidos a sus verdaderos mentores en el arte arquitectónico.

Pocos meses después de su traslado a Barcelona en 1859, contrae matrimonio con la hija adoptiva de su tío Ramón Guastavino Buch (1815-1871), $\mathrm{M}^{\mathrm{a}}$ Francisca Buenaventura el 18 de agosto de 1859. ${ }^{55}$ En el acta matrimonial se refleja su profesión de carpintero, aunque se desconoce dónde trabajaba. El 28 de julio de 1861, al hilo del nacimiento de su segundo hijo Ramón, ${ }^{56}$ Rafael Guastavino Moreno ya consta documentalmente como maestro de obras ${ }^{57}$ y así iba a ser en el resto de inscripciones de nacimiento de sus otros hijos Manuel ${ }^{58}$ y Rafael, ${ }^{59}$ hasta su marcha a Nueva York en marzo 1881. Llama la atención que en fechas tan tempranas se le registre como maestro de obras. No es descartable que la mención en los registros municipales como maestro de obras se deba a su ingreso en $1861^{60}$ en la Escuela Especial de Maestros de Obra. En cualquier caso, es fácil que su destreza y familiaridad con el arte de la carpintería y su puesta en obra, en la realidad le facilitara el acceso a los trabajos que tuvo como dibujante en un estudio de arquitectura de Valencia, ${ }^{61}$ como ayudante en el estudio de arquitectura de Jeroni Granell i Mundet (1834-1890) y Antoni Robert i Morera ( $i$-1878) de Barcelona ${ }^{62}$ hasta $1862^{63}$ y como ayudante de ingeniero en una fundición de Barcelona en algún momento durante su época de estudiante (1861-1863). ${ }^{64}$ En aquellos años, la línea que separaba el ejercicio profesional entre maestros carpinteros y maestros de obras era bastante difusa y se podían producir solapes en obras menores para los maestros carpinteros. Además, cabe destacar la importancia de la madera como material de construcción, desde las primeras labores de replanteo hasta las guías para respetar la forma de las bóvedas, pasando por la construcción de andamios.

Curiosamente, en Estados Unidos demostró sus conocimientos en la materia cuando tuvo que erigir para sí mismo dos edificios con madera: su propia casa rural en Black Mountain (Carolina del Norte), con estructura, muros y revestimiento de madera (1894-1895); ${ }^{65}$ y su fábrica de cerámica en Woburn (Massachusetts) (Fig. 2), una construcción claramente influida por la arquitectura de Henry Robson Richardson (1838-1886) en gruesa mampostería de cantos rodados con cubierta de madera que alojaba los hornos cerámicos (1906-1907). ${ }^{66}$ Después de dos décadas demostrando a lo largo y ancho de la Costa Este, las ventajas de construir con materiales resistentes al fuego, como el yeso, el ladrillo y el cemento, resulta interesante que recurriera a la madera para estas dos construcciones propias. La razón de esta elección residía probablemente en la economía. Por otra parte, es paradójico que ambas construcciones, de la mano de

${ }^{55}$ ACB, Matrimonis, Registres, 1859, vol. 304, folio 282r, núm. 1126, 18-VIII-1859. Más tarde adoptaría el nombre de Pilar Guastavino López.

${ }^{56}$ ACB, Naixements, Registres, 1861, Llibre 3, fol. 216v, núm. 3428, 23-VII-1861.

57 Rafael Guastavino Moreno no recibió el título de maestro de obras de manera oficial hasta 1872, según noticia de prensa de la época, en la que se dice que el señor director del Instituto provincial de segunda enseñanza de Barcelona, confirió el grado de maestro de obras a 22 estudiantes entre los que consta Rafael Guastavino. La Independencia (Barcelona), 5-VII-1872.

${ }^{8}$ ACB, Naixements, Registres, 1863, Llibre 4, fol. 84v, núm. 5130, 23-VII-1861.

${ }^{59}$ ACB, Naixements, Registres, 1872, Llibre 2, p. 642, núm. 3428, 23-VII-1872.

60 ROTAECHE, M., 2013, p. 950.

61 GUASTAVINO IV, R., 2006. p. 1. También: MILETO, Camilla; VEGAS, Fernando, 2012, p.136.

62 MILETO, Camilla; VEGAS, Fernando, 2012, p. 137.

${ }^{63}$ WIGHT, Peter B. "The works of Rafael Guastavino. Part I: As architect". The Brickbuilder, Abril 1901, p. 79.

${ }^{64}$ Anónimo. "Valencianos sobresalientes. Nuestros arquitectos: Rafael Guastavino". Las Provincias (Valencia), 20-IX-1898.

${ }^{65}$ OCHSENDORF, John Allen, 2014, p.113.

66 OCHSENDORF, John Allen, 2014, p. 88. 
un arquitecto que fundamentó su carrera en las propiedades ignífugas de su sistema constructivo, fueran con el tiempo pasto de las llamas, a saber, su fábrica de Woburn en 1915 y su casa en Black Mountain, años después de su muerte. ${ }^{67}$

\section{Tercer acto: La vitivinicultura}

Los clientes de Rafael Guastavino en Barcelona fueron pequeños o grandes empresarios de la pujante burguesía catalana de la época a quienes sin duda tuvo acceso inicialmente a través de su tío y suegro Ramón Guastavino Buch (1815-1871), fundador junto a Pedro Bosch Labrús (1827-1894) de la saneada cadena de almacenes textiles El Águila. ${ }^{68}$ Pedro Bosch Labrús era socio a la sazón de Joan Güell Ferrer (1800-1872), fundador a su vez de la empresa metalúrgica La Maquinista Terrestre y Marítima, que suministró las columnas de fundición al menos para la Fábrica Batlló (1868-1870) de Rafael Guastavino, ${ }^{69}$ y padre del más conocido Eusebi Güell Bacigalupi (1846-1918) -por su mecenazgo de Gaudí-, para quien Rafael Guastavino Moreno diseñaría los planos de la fábrica de cementos Asland del Clot del Moro (1901-1903) en Castellar de N'Hug (Barcelona) desde Estados Unidos. ${ }^{70}$ Es oportuno recordar además, que Eusebi Güell tenía ascendencia inmediata ligur por parte materna (Bacigalupi), al igual que Rafael Guastavino la tenía por parte paterna (Guastavino). El encargo de la Fábrica textil Batlló le llegó probablemente a través del contacto de su tío Ramón con la familia Batlló que había hecho fortuna gracias a los viajes de prospección de Juan Batlló Barrera (1812-1892) en Sudamérica. ${ }^{71}$ Entre los clientes de Guastavino se pueden contar también Víctor Blajot (Casa Blajot), perteneciente a una saga de comerciantes catalanes con negocios en Puerto Rico; Lorenzo Oliver Soler (1822-1885) (Palacete Oliver), comerciante originario de Mahón que había emigrado a Monterrey, México, donde se había hecho rico; ${ }^{72}$ o Juan Federico Muntadas Jornet (1826-1912), escritor y terrateniente, hijo del empresario Pau Muntadas Campeny (1797-1870), fundador de la sociedad España Industrial, propietarios ambos del Monasterio de Piedra (Zaragoza), ${ }^{73}$ cuya gruta de la Cascada de Caballo se convertiría en una inspiración para las bóvedas cohesivas de Rafael Guastavino. ${ }^{74}$ Para esta familia estudió la posibilidad de convertir el famoso monasterio en una hospedería, y diseñó además la fábrica de aprestos Muntadas, Aparicio \& Cía (1875) en Barcelona. ${ }^{75}$

Muchos de estos empresarios catalanes estuvieron vinculados en política: Joan Güell fue diputado en las Cortes Españolas (1857-1862) por los moderados de la Unión Liberal, regidor en el Ayuntamiento de Barcelona y senador por designación real (1862-1868); su hijo Eusebi Güell perteneció a la Lliga Regionalista y fue concejal del Ayuntamiento de Barcelona (1875-1878), diputado provincial (1878) y senador del Reino; Pedro Bosch Labrús fue diputado a Cortes (1876-1886, 1891-1893); Juan Federico Muntadas fue diputado a Cortes (18581864), etc. Generalmente, la ideología de todos ellos era moderadamente conservadora $y$, sobre todo, proteccionista y defensora de los intereses industriales catalanes.

Además, cabe destacar que algunos de estos empresarios catalanes (Güell padre, Batlló, Blajot, Oliver) eran indianos que habían amasado una considerable fortuna en ultramar. Incluso, los hermanos del arquitecto, Antonio Guastavino Moreno, ${ }^{76}$ al

\footnotetext{
67 Woburn Daily Times, 2-VI-1915.
}

68 OLIVA i RICÓS, Benet, 2009.

69 Carta de pago firmada en 1870 por la empresa y los Hermanos Batlló (AHPB, 1312/57: Ferran Ferran Sobregues, ápoca de las sociedades "La Maquinista" e "Ignacio y Casimirio Girona", núm. 161, f. 576-581, 11/05/1870), citada por LUENGO PÉREZ, Noelia; VEGAS, Fernando; MILETO, Camila, 2016, pp. 393-402.

70 TARRAGÓ, Salvador, 2002, pp. 12-15; OCHSENDORF, John Allen, 2014, p. 240.

71 En: http://www.jeronimosunol.net/esp/inicio/batllo.htm (Fecha de consulta: 26-03-2017).

72 ALVIRA BANZO, Julio. "Contenson y Oliver, dos pioneros en la mecanización agraria oscense". Diario del Alto Aragón, 10VIII-2009, pp. 34-35.

73 MUNTADAS, Juan Federico. El Monasterio de Piedra. Zaragoza: Torres \& Associats S.L. [1871], 2002.

74 GUASTAVINO IV, Rafael, 2006, pp. 14-15.

75 ROSELL, Jaume, 1995, reeditado en: HUERTA, Santiago (ed.), 2001, p. 202.

${ }^{76}$ Ya se ha dicho que Antonio estuvo en Cuba de forma intermitente desde 1868 e ininterrumpidamente entre 1871 y 1875 como organista y maestro de capilla de la catedral de Santiago de Cuba. Desde este momento se le pierde la pista hasta 1878 que embarca en el puerto mexicano de Tampico dirección a Nueva Orleans donde llega el 6 de marzo, En: https:/familyse arch.org/ark:/61903/1:1:QKNP-LVT6. № de Microfilm 000200201 (Fecha de consulta: 16-IV-2016). Más tarde, hacia 1881 residía en Londres casado y con una hija, donde daba clases de música. https://familysearch.org/ark:/61903/1:1:Q277-MGNW. N de Microfilm 101774371 (Fecha de consulta: 16-IV-2016). Ya en 1891 vistió el hábito de la orden franciscana en el convento de Santo Espíritu del Monte (Valencia). Falleció finalmente en el convento franciscano de Segorbe (Castellón) el 8-II-1919. 
menos entre 1869 y 1875, y José Guastavino Moreno, ${ }^{77}$ entre 1871 y 1898, residieron también un tiempo en la isla de Cuba. Las relaciones con la isla de Cuba en aquel momento eran bien fluidas. Curiosamente, el héroe de la independencia cubana José Martí (1853-1895), hijo de Mariano Martí (1815-1887), natural del barrio de Campanar $^{78}$ de Valencia y de Leonor Pérez Cabrera (1828-1907), natural de la isla de Tenerife, se trasladó en tierna infancia con su familia a Valencia en 1857 donde permaneció hasta $1859 .{ }^{79}$ La familia Martí y la familia Guastavino fueron vecinos cuando estos residían en la calle Verónica número 7. En este momento José Martí contaba seis años de edad, así que con toda probabilidad pudo asistir durante su estancia en Valencia, a la misma escuela de enseñanza primaria donde iban los hermanos pequeños de Rafael en edad escolar, Carlos y Juana, ubicada en la cercana calle Ancha de la Platería (actual calle Numancia). El niño José Martí regresó en 1859 a Cuba y diez años después iniciaría su periplo a favor de la independencia de Cuba que le llevaría a residir en múltiples ciudades de países diversos, entre ellas, la ciudad de Nueva York.

Es fácil que este tráfico consuetudinario con ultramar y el ejemplo de los empresarios catalanes hayan servido de acicate para que en 1881 Rafael Guastavino hiciera las Américas. La isla de Cuba no parecía antaño un destino adecuado, dado que los tiempos estaban bastante revueltos con la
Guerra de los Diez Años (1868-1878) y la Guerra Chiquita (1879-1880), primera y segunda guerras de la independencia cubana respectivamente, que iniciaron a su antiguo vecino José Martí como dirigente del pueblo cubano. En cambio, Estados Unidos había demostrado un enorme potencial de crecimiento en la Exposición del Centenario de Philadelphia de 1876, donde además Rafael Guastavino participó con sus proyectos ganando una medalla. ${ }^{80}$

Uno de estos clientes y empresarios catalanes de Rafael Guastavino, Lorenzo Oliver Soler, se convirtió además en buen amigo y compañero de inversiones para el arquitecto. En paralelo a la construcción del desaparecido Palacete Oliver (1869) en el Paseo de Gracia de Barcelona, Lorenzo Oliver adquirió en Almudévar (Huesca) 667 hectáreas entre 1868 y 1870 que destinó a partes iguales al cultivo de la vid y de cereales en la que vendría a denominarse Colonia de San Juan. ${ }^{81}$ Poco después, aprovechando la herencia recibida tras el fallecimiento en 1871 de su tío-suegro Ramón, Rafael Guastavino adquirió un terreno adyacente a las de su amigo Oliver $^{82}$-que sumado a otros que fue adquiriendo a lo largo de varios años hasta $1879-{ }^{83}$ darían como resultado la fundación de la Colonia de San Ginés en 1880 para la explotación vitivinícola, cuya dimensión total era del 297 fanegas, equivalentes a 21 hectáreas con 27 áreas. ${ }^{84} \mathrm{El}$ polígrafo Joaquín Costa (1846-1911), que había trabajado en su juventud como albañil en la finca

77 José nació el 24-IV-1845 y fue bautizado en Santa Catalina (AHMV, Registro de nacimientos, Película 1174, $n^{\circ} 1164$ ). En 1871 emigró a Cuba, cuando militaba en las filas del partido progresista-democrático de Barcelona. Véase: (La Iberia, Madrid, 29-XI-1871). Fue nombrado por R.O. de 1873 capellán castrense de Instrucción del Primer Regimiento de Infantería. No se tiene constancia que disfrutara de permisos durante sus casi 30 años de servicio en Cuba, que le permitiese volver a la Península. Sí los disfrutó ya de vuelta en nuestro país después de 1898. Recibió la baja de su cargo de Teniente Vicario de $2^{\mathrm{a}}$ del Clero Castrense por jubilación reglamentaria el 24-IV-1907. Vivió en Burjassot y Valencia hasta su fallecimiento el 20-I-1920. Datos obtenidos de su hoja de servicios conservada en: AGMS, 1'a, 4065G, Exp. 02.

78 AGMS, Sección Primera, 935M, Exp. 7.

79 AHMV, Padrón General, Año 1859, Legajo 102, Distrito Mercado, Barrio 3. José Martí y su familia vivían en la manzana de atrás, concretamente en la calle Tapinería número 26 (AHMV, Padrón General, Año 1858, Legajo 98, Distrito Mercado, Barrio $5^{\circ}$ ).

80 Véase: VEGAS, Fernando, 2001, p. 257.

81 ALVIRA, Julio. "Joaquín Costa y el Monte de San Juan (1864-1895)". Diario del Alto Aragón, 10-08-2011, p. 34.

82 AHPHU, Protocolos, 10.496, not. Mariano Armisen, núm. 26, ff. 85r-92v, 17-I-1872.

${ }^{83}$ Además de la escritura ya citada, se han encontrado otras cinco escrituras otorgadas en Huesca y Almudévar, en las que se recogen las porciones de terreno que adquirió Rafael Guastavino a sus respectivos propietarios, para configurar la Colonia de San Ginés. En orden cronológico son: AHPHU, Protocolos, 10.610, not. Marcelino Ornat Pérez (Almudévar), núm. 51, ff. 143r149v, 2-IV-1872; AHPHU, Protocolos, 10.499, not. Mariano Armisen (Huesca), núm. 150, ff. 564r-565v, 4-IV-1873; AHPHU, Protocolos, 10.503, not. Mariano Armisen (Huesca), núm. 499, ff. 2022r-2024v, 27-XII-1874; AHPHU, Protocolos, 10.613, not. Marcelino Ornat Pérez (Almudévar), núm. 1, ff. 1r-6r, 2-I-1875; AHPHU, Protocolos, 10.517, not. Mariano Armisen (Huesca), núm. 26, ff. 765r-768v, 1-VII-1879.

${ }^{84}$ AHPB, 1348/40, not. Antoni Doménech i Oliveras, manual 1880-IV, núm. 535, ff. 2271r-2282r 6-X-1880. Referencia facilitada por Benet Oliva i Ricós. 
agrícola de San Juan, llegó a ser buen amigo de Lorenzo Oliver y, probablemente también, de Rafael Guastavino. ${ }^{85}$

Las razones de esta inversión agrícola pueden ser varias. La inestabilidad política y económica del Sexenio Democrático (1868-1874) tras la revolución de septiembre de 1868, especialmente en ciudades como Barcelona y Valencia, seguramente inclinó a invertir en el campo, lejos de las algaradas y las revueltas urbanas que dificultaban las inversiones inmobiliarias. Al mismo tiempo, la epidemia de la filoxera (Dactylosphaera vitifoliae) había hecho su primera aparición en Francia en 1863, reduciendo drásticamente la producción en este país, y el negocio de producción de vino se antojaba de gran prosperidad en el nuestro. La consideración de un terreno agropecuario como colonia agrícola poseía ventajas especiales. ${ }^{86}$ Este reconocimiento de los beneficios de la ley sobre población rural por las propiedades de Lorenzo Oliver Soler y Rafael Guastavino tuvo lugar en 1878 de manera simultánea. ${ }^{87}$
La colonia de San Ginés pertenecía al término municipal de Huesca y estaba situada a unos nueve kilómetros al sur de la capital oscense. Actualmente estos terrenos quedan al sureste de la Autovía Mudéjar que une Huesca con Zaragoza, muy próximos al Castillo de San Luis, ${ }^{88}$ una finca actualmente destinada a grandes eventos y celebraciones. ${ }^{89}$ Originalmente, la Colonia de San Ginés poseía tres grupos de edificios y construcciones auxiliares de mampostería que el arquitecto Rafael Guastavino Moreno erigió y/o acondicionó, por desgracia, hoy en ruinas: el primero, una casa de labranza de dos alturas con sus cuadras y su pajar; el segundo, un edificio también de dos alturas, destinado a bodega y almacenes; y el tercero, un molino harinero de tres alturas con habitaciones para el molinero, cuadras, con un arroyo caudaloso a sus pies. ${ }^{90}$ La forma y los lindes originales quedan definidos en el plano adjunto ${ }^{91}$ a la escritura $^{92}$ (Fig. 3).

Tras analizar la descripción gráfica y literaria del documento notarial por un lado, y por otro la car-

85 La finca agrícola fue adquirida a los hermanos Seller, que habían empleado a Hilarión Rubio, maestro de obras municipal de Huesca, y nada menos que a un joven Joaquín Costa de albañil entre 1863 y 1867 para la construcción, reparación e incluso el diseño de una bodega con una memoria sobre viticultura y vinificación. Véase ALVIRA, Banzo. "Joaquín Costa y el Monte de San Juan (1864-1895)", Diario del Alto Aragón, 10 de agosto de 2011, p. 34.

86 ALVIRA BANZO, Julio. "Contenson y Oliver, dos pioneros en la mecanización agraria oscense". Diario del Alto Aragón, 1008-2009, pp. 34-35.

87 El Diario de Huesca, 7-VI-1878. Hay constancia documental de su solicitud al Ayuntamiento de Huesca para la aplicación de los beneficios del Artículo 26 de la Ley 3 de junio de 1868, en el expediente: AHMHU, Adm. 5.954 LALA. Con anterioridad, la prensa local se hacía eco de la intención de Rafael Guastavino con otra noticia publicada en: El Diario de Huesca, 15-X-1876.

88 El Castillo de San Luis fue propiedad en aquellos años del diplomático y militar francés el barón Guy de Contenson (18441921), que junto a su mal avenido vecino Lorenzo Oliver Soler, fueron los dos pioneros de la introducción de la maquinaria a la explotación agrícola. Rafael Guastavino, que formaba parte de ese proyecto de innovaciones agrícolas, emigró a Estados Unidos antes de que se pusieran completamente en marcha. Véase ALVIRA BANZO, Julio. "Contenson y Oliver, dos pioneros en la mecanización agraria oscense". Diario del Alto Aragón, 10-08-2009, pp. 34-35.

89 Para llegar se debe tomar la salida 352 en sentido creciente de la Autovía Mudéjar A-23 E-07.

90 AHPB, 1348/40, not. Antoni Doménech i Oliveras, manual 1880-IV, núm. 535, ff. 2271r-2282r 6-X-1880. Referencia facilitada por Benet Oliva i Ricós.

91 Dicho plano (Fig. 2) es copia del original, ambos realizados por D. Rafael Luna y Rey y D. Tiberio Sabater y Carné, agrimensores y maestros de obras por la Academia de Bellas Artes de Luis de Zaragoza. Se realizó con el objeto de hacer constar con la exactitud debida la situación, figura, medida, obras de fábrica, linderos y demás que constituyen la finca. Los mismos técnicos que firmaron el plano, tasaron la propiedad del arquitecto Rafael Guastavino en ciento ocho mil setecientas setenta y cinco pesetas. La lectura exclusiva de este plano no ha permitido precisar la ubicación actual de lo que un día fue la Colonia de San Ginés. Para ello ha sido necesario apoyarse en cartografía histórica del término municipal de Huesca. Se trata de: Plano General del Término Municipal de Huesca a escala 1:20.000 y hoja de detalle número 11 del anterior a escala 1:5.000, ambos realizados por el ingeniero topógrafo Dionisio Casañal en 1891 y disponibles en: http://www.huesca.es/areas/archivo-munici pal/plano-1891/descarga-de-planos/; Minuta Cartográfica con referencia PLANI220278_1926_HUESCA, destinada a la formación de los mapas a escalas 1:25.000 y 1:50.000. Se encuentra disponible en: http://centrodedescargas.cnig.es/CentroDescar gas/buscar.do?filtro.checkCoord=N\&filtro.codFamilia=MIPAC\&filtro.codCA=\&filtro.codProv=\&filtro.nombreBis=Municipio\&fil tro.codlne=34022222125\&filtro.numeroHoja= (Fecha de consulta (14-II-2017); y el Mapa Nacional Topográfico Parcelario realizado a escala 1:5.000, Polígono 21, del Instituto Geográfico Catastral ejecutado en 1963, conservado en el Dpto. de Urbanismo del Ayuntamiento de Huesca.

92 Continúa el documento diciendo que lindaba "al norte con cuarto Barranco o sea monte Barranco, al Sud con cuarto o sea monte Barreras; al Este con tierras del Sr. Claver al Oeste con tierras Dña. María Pérez. Que la atraviesa y alimenta su regadío la acequia principal denominada de Pebredo". Por último, la dimensión total de la Colonia era de "una superficie de doscientas noventa y siete fanegas, equivalentes veintiuna hectáreas veintisiete áreas y hallase destinada dicha finca al cultivo de cereales, viña y huerto, correspondiente a tres hectáreas cuarenta áreas a viñedo; una hectárea y cuarenta y cinco hectáreas a 


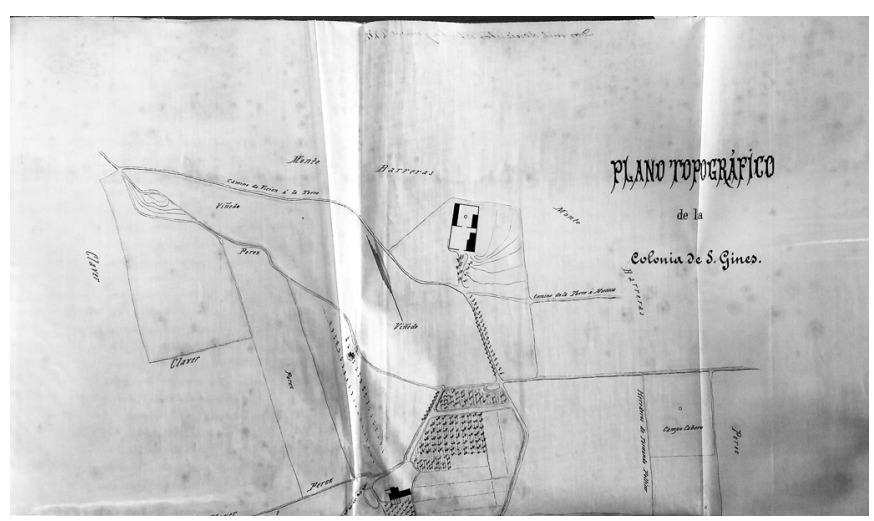

Fig. 3. Detalle del plano de la Colonia de San Ginés. Rafael Luna y Rey y Tiberio Sabater y Carné, 1880. AHPB. Foto: Víctor M. Cantero.

tografía histórica citada, surgen dudas acerca de las construcciones originales existentes y su verdadera ubicación. Se acentúan las dudas después de la exploración in situ de las ruinas. Hoy en día solo existen vestigios de un grupo de edificaciones, no de tres como describen las escrituras y así corrobora la cartografía histórica. Lo que queda en pie, a su vez está formado por tres volúmenes principales bien definidos, alineados según la dirección este-oeste, que son: primero, una edificación de planta rectangular con una puerta en el centro de uno de sus lados mayores orientado al norte y dos ventanas a cada lado, que bien pudiera ser la vivienda, en la que se adivina una cubierta a dos aguas cuya línea de cumbrera seguiría la dirección norte-sur; a continuación, un segundo bloque cuya línea de fachada se encuentra retranqueada con respecto a la del bloque anterior, muy compartimentado en su interior, que podría ser la bodega; y en tercer lugar otro volumen, el mejor conservado de los tres, de planta rectangular con cubierta a un agua orientada al norte, con una puerta en su fachada norte, y que en el exterior del lado oeste descansa una piedra troncocónica tradicionalmente utilizada para la molienda de grano para fabricación de harina, despejando las dudas sobre el uso al que estaba destinado este tercer volumen.

Siendo así, ¿a qué correspondían los otros dos grupos de edificaciones hoy totalmente desaparecidos? No es posible dar una respuesta satisfactoria por el momento. Pero a tenor de una noticia de prensa de la época, lo que no deja lugar a dudas, es que José Guastavino, el primogénito de Rafael, pasaba largas temporadas residiendo en la colonia. ${ }^{93}$ También habitó en ella el segundo de sus hijos, Ramón, como se desprende de una solicitud presentada por él mismo al Ayuntamiento de Huesca ${ }^{94}$ en 3 de noviembre de $1877^{95}$ para la reparación del camino de Cuarte a Vicién que discurría cercano a la finca agrícola.

El objetivo de la fundación de la Colonia de San Ginés por parte de Rafael Guastavino era la producción de vino y su comercialización. Efectivamente, llegó a establecer junto a su cuñado Ramón Alfaro Molina, un establecimiento de vinos ${ }^{96}$

secano y diez y seis hectáreas cuarenta y una áreas de regadío alimentado por la acequia que atraviesa la finca llamada acequia de Pebredo = El regadío se halla dividido en huerta, cereales y arbolado, compuesta este de campos de perales, moreras y otros". AHPB, 1348/40, not. Antoni Doménech i Oliveras, manual 1880-IV, núm. 535, ff. 2271r-2282r 6-X-1880. Referencia facilitada por Benet Oliva i Ricós.

${ }^{93}$ Gaceta de Madrid, 29-III-1880.

${ }^{94}$ En ella se solicita que se acometan las obras de reparación pertinentes en el camino de Cuarte a Vicién, que discurría a escasos metros de las edificaciones, y que había quedado intransitable para carros y vehículos de agricultura empleados en la conducción de semillas y estiércoles, debido a la fuerza de las lluvias torrenciales que habían tenido lugar entonces recientemente. AHMHU, Adm. 5.965, LALA.

95 Resulta cuanto menos singular cómo sus tres hijos mayores, José (1859-1905), Ramón (1861-¿?) y Manuel (1863-¿?), que emigraron a Argentina con su madre, optaron por dedicarse allí a las tres profesiones de su padre, a saber respectivamente, arquitecto, empresario vitivinícola en Mendoza y constructor. El cuarto hijo, Rafael (1872-1950) que emigró con él a Estados Unidos, fue arquitecto y constructor como es sobradamente conocido.

${ }^{96}$ BENET i RICÓS, Benet, 2009. Ramón Alfaro Molina (1846-1908 ca.) nació en Sesa (Huesca). Todo apunta a que Rafael Guastavino conoció a Ramón Alfaro a principios de la década de los setenta durante sus frecuentes estancias en Huesca y con posterioridad le animó a trasladarse a Barcelona, donde por circunstancias de la vida acabó casándose con su hermana Juana Guastavino Moreno. Ramón era ebanista de profesión y se casó con Juana el 17 de diciembre de 1879 en la parroquia de la Purísima (ACB, Matrimonis, 1879, Registres, Vol. 346, p. 1202, núm. 2402). De su matrimonio nacieron seis hijos, Antonia (1880), Ramón (1882), Julia (1885), José Ramón (1888), Pascual (1892) y Luis (1893), todos ellos en Barcelona. Se desconocen los avatares que sufrió el matrimonio pero lo cierto es que en 1908 Juana acabó emigrando con sus hijos Antonia y Pascual a Nueva York, donde les estaban esperando su otro hijo José Ramón que viajó en 1905, y Rafael Guastavino padre e hijo. Llegaron apenas a tiempo de ver con vida a Rafael Guastavino, pues tan solo ocho días después fallecería. Ramón debió quedarse en Barcelona, pues en la hoja de embarque de Juana y sus hijos se anotó como familiar de referencia en Barcelona a un tal Alfaro residente en la calle Muntaner $n^{\circ} 19$. 
y licores en Madrid situado en la calle de Atocha número 88 en el año $1881 .{ }^{97}$ La empresa vitivinícola de Rafael Guastavino no sólo llegó a comercializar el denominado vino Guastavino ${ }^{98}$ del Alto Aragón, sino que hasta recibió reconocimiento internacional. ${ }^{99} \mathrm{El}$ anuario del comercio de Carlos Bailly-Bailliere ya referido informa en su edición del año 1880 de un establecimiento de vinos situado en la calle Correos $n^{\circ} 4$ de Madrid, propiedad de un individuo Ilamado Ramón Molina. No ha sido posible determinar si esta persona es efectivamente Ramón Alfaro Molina, ni tampoco localizar la licencia de apertura de dicho comercio. ${ }^{100}$

Apenas llegado a Nueva York, Rafael Guastavino se topó con enormes dificultades para encontrar productos a los que estaba acostumbrado en España, como el aceite de oliva, el tabaco de fumar o el vino. ${ }^{101}$ Quizás esta sea la explicación de que, una vez su amante Paulina Roig abandonara definitivamente los Estados Unidos por incapacidad de adaptarse, ${ }^{102}$ Rafael Guastavino buscara consuelo en la mexicana Francesca Ramírez, más cercana a su cultura de origen que las mujeres anglosajonas, mexicana con la que terminaría casándose en segundas nupcias, ${ }^{103}$ tras el fallecimiento de su primera mujer en Argentina, ${ }^{104}$ y viviendo los últimos años en su rancho Rhododendron de Black Mountain (Carolina del Norte). Se debe destacar que su rancho incluía la casa de madera, apodada localmente como "The Spanish Castle", de la cual quedan hoy solo los cimientos; unos hornos cerámicos experimentales que existen todavía con su chimenea; un estanque de piscicultura -imitación probablemente de la primera piscifactoría de España que había creado en 1867 en el Monasterio de Piedra Juan Federico Muntadas Jornet, ${ }^{105}$ una barbacoa construida de obra no tanto para asar carne al estilo local sino para hacer paellas, en lo que era sin duda una reivindicación de sus orígenes; ${ }^{106}$ y un amplio terreno para el cultivo de la vid, un lagar de vino y unas bodegas, todavía existentes, donde producir vino para consumo personal y agasajo de sus visitantes. ${ }^{107}$

\section{Cuarto acto: La arquitectura}

Este artículo no pretende ser la sede para hacer un tratado de arquitectura de Guastavino, pero sí sugerir nuevas claves para comprender su aportación personal a la técnica tradicional de la bóveda tabicada que le permitió proyectarla a la construcción de la ciudad contemporánea. Como se ha apuntado, el ejemplo de su tatarabuelo Juan José Nadal (1690-1763) había pesado en su elección por la arquitectura en detrimento de la música. Juan José Nadal, perteneciente a una familia de judíos conversos que se venía dedicando a la construcción al menos desde el siglo XVI, tuvo como mínimo dos hijos varones de su primer matrimo-

97 Anuario del Comercio de la Industria de la Magistratura y de la Administración o Directorio de las 400.000 señas de Madrid, de las provincias, de Ultramar, de los Estados Hispano-Americanos y de Portugal. Madrid: Carlos Bailly-Bailliere, 1881, p. 128. Teniendo en cuenta que llegó a los Estados Unidos en abril de este año y que no existe licencia de apertura de comercio en el Archivo de la Villa de Madrid, se estima que su salida urgente paralizó las gestiones para formalizar dicho establecimiento.

98 La cacofonía seguramente redundó en un nombre comercial pegadizo. Sin embargo, la ironía del apellido Guastavino (literalmente "estropeavino" en italiano original), ya señalada en GUASTAVINO IV, R., 2006, p. 40 convertía la denominación en una verdadera paradoja, al menos, a oídos de un italiano.

99 La llustración española y americana, № XXXII, 30-VIII-1881, p. 127. Refleja la mención de los premios obtenidos por los industriales que han remesado sus productos por vapores españoles a la Exposición de Matanzas (Cuba) que fue clausurada el 3 de julio de 1878. Le fue concedida la medalla de bronce.

100 A tenor de los datos ofrecidos por el padrón histórico del Archivo de la Villa de Madrid, existe un local destinado a tienda, pero que se encuentra "desalquilado" tanto en el año 1880 como en el inmediatamente anterior y posterior.

101 GUASTAVINO IV, R., 2006, p. 12.

102 Antes de volver definitivamente a la Península, hemos encontrado al menos un nuevo embarque desde el puerto de Barcelona de Paulina y sus dos hijas Francisca y Engracia hacia Nueva York, con llegada a Ellis Island el 3 de marzo de 1882.

103 GUASTAVINO IV, 2006, p. 36. Para ver el documento de índice de matrimonios en el que consta el de Rafael y Francesca véase: www.familysearch.com record-image_3QS7-89MB-YW1L (Fecha de consulta: 16-IV-2016).

104 A decir verdad, todo parece indicar que Rafael Guastavino montó una farsa en torno a la muerte de su primera mujer Pilar Guastavino para justificar la legitimidad de su matrimonio con Francesca celebrado en Boston el 12-IX-1894. Así lo confirma un censo de población de Buenos Aires en 1895, donde Pilar no solo aparece con vida domiciliada en la población rural de La Dormida en la provincia argentina de Mendoza, sino que su estado civil es casada. Lo que no se ha podido confirmar es si rehízo su vida en Argentina y se volvió a casar o mantuvo su estado civil en memoria de Rafael.

105 MUNTADAS, J.F. [1871], 2002.

106 GUASTAVINO IV, R., 2006, p. 49; OCHSENDORF, John Allen, 2014, p. 114

107 GUASTAVINO IV, R., 2006, p. 49; OCHSENDORF, John Allen, 2014, p. 114. 


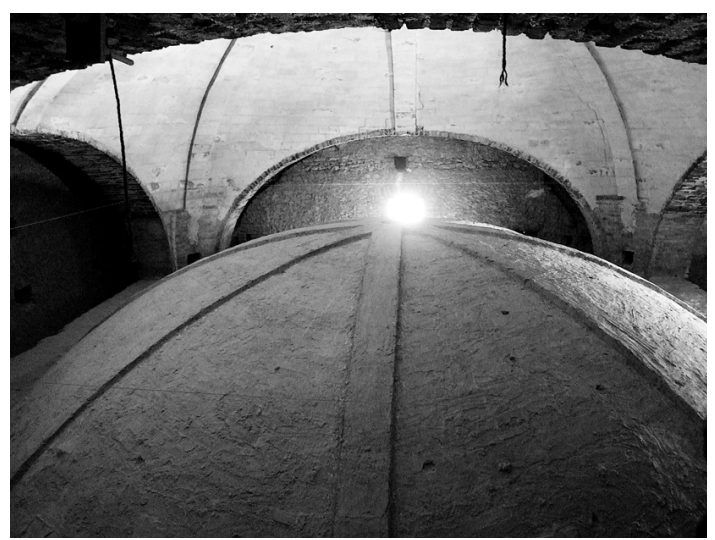

Fig. 4. Espacio bajo la cubierta de la iglesia parroquial de San Jaime de Vila-Real (Castellón), que revela la maestría de Juan José Nadal en el manejo de la bóveda tabicada. Foto: Vegas \& Mileto.

nio (uno de ellos llamado Jaime), que adoptaron la profesión de constructor y le ayudaron en sus obras. ${ }^{108} \mathrm{Al}$ enviudar, se casó en segundas nupcias con Leonor Puigvert (¿?-1772), con la que tuvo una única hija, Pasquala Nadal Puigvert, que alumbró a su vez a la abuela del arquitecto Rafael Guastavino Moreno, Ilamada Josefa Ebrí Nadal (1786-1854).

La fama de Juan José Nadal y su participación en la construcción de nada menos que 22 templos, alguno de ellos con envergadura de catedral, como la parroquia de San Jaime de Villarreal (Castellón) (Fig. 4), debe haber sido conocida por los descendientes de la familia.

Es incluso posible que se tuviera contacto todavía con la rama de los hijos varones de Juan José Nadal, que había continuado con la profesión. De hecho, siguen siendo confusas las alusiones de Peter B. Wight ${ }^{109}$ y de Rafael Guastavino IV $^{110}$ a la existencia de un contemporáneo llamado José Nadal, que podría ser perfectamente compatible con la existencia ya demostrada fehacientemente de su tatarabuelo Juan José Nadal. ${ }^{111}$ De hecho, a falta de mayores datos, resulta muy sospechoso que la casa de la calle Puñalería donde residió alquilada la familia Guastavino-Moreno entre 1840 y $1844^{112}$ y donde nació Rafael Guastavino Moreno en 1842 fuera propiedad de un escribano, tasador y regidor de Valencia llamado José Nadal (17991843). ${ }^{113}$ Este José Nadal, de cuya existencia -sin saber entonces que había sido el arrendador de la vivienda de los Guastavino- y entrada el 11 de noviembre de 1842 en la Real Sociedad Económica de Amigos del País ${ }^{114}$ ya se dio cuenta en un anterior artículo, ${ }^{115}$ falleció en Valencia el 29 de enero 1843 en su casa de la calle de Gracia número veinte, cuando Rafael Guastavino Moreno tenía menos de un año edad. En un futuro sería interesante poder demostrar una eventual relación de parentesco con esta otra familia Nadal, lo cual explicaría aún mejor si cabe la transmisión de la memoria del mítico tatarabuelo constructor, a través de alguno de sus hijos varones que sí conservaron el apellido.

Pero Rafael Guastavino no solo recoge el relevo de un ilustre antepasado avezado alarife del que hereda los arcanos de la bóveda tabicada probablemente trámite algún pariente coetáneo, sino que aporta además de su propia cosecha introduciendo en la técnica tradicional un conglomerante antaño de reciente invención, el mortero de cemento, que era más impermeable y fraguaba más rápido que el mortero de cal. En efecto, Rafael Guastavino emplea durante toda su vida profesional la pasta de yeso para construir el primer estrato de ladrillos y el mortero de cemento en detrimento del mortero de cal para los sucesivos estratos superiores.

En sus escritos, Rafael Guastavino demuestra un conocimiento notable sobre los morteros, en general, y los morteros de cemento, en particular. ${ }^{116}$

\footnotetext{
108 MILETO, Camilla; VEGAS, Fernando, 2012, p. 142.

109 WIGHT, Peter B. "The Works of Rafael Guastavino. Part I-As Architect", The Brickbuilder, April, 1901, p. 79.

110 GUASTAVINO IV, R., 2006, p. 1.

111 MILETO, Camilla; VEGAS, Fernando, 2012, pp. 138-141.

112 AHMV, Padrón General, Año 1840, Legajo 20, Cuartel del Mercado, Barrio 3.

113 AHMV, Registro de defunciones, Microfilm n 1525. Había nacido en Onteniente, era hijo de Francisco Nadal y de Anastasia Lizandro naturales de Onteniente y Xàtiva respectivamente.

114 RSEAPV, Libro de Juntas de 1839 a 1843. La verdadera fecha de su aceptación como socio de la sociedad fue en la Junta General del 11 de noviembre y no en la del día 18.

115 VEGAS, Fernando, 2001, p. 257.

116 GUASTAVINO MORENO, Rafael. Prolegómenos á las Funciones de la Mampostería en las Modernas Construcciones Arquitectónicas, texto en castellano sin fecha (prólogo firmado en New York, Noviembre 1895), B.N.E. Sede Recoletos 1/9289, Código de barras 1103203488; Sede Alcalá DGMICRO/30749, Código de barras 3974888-2001.
} 
Argumenta preferir el mortero de cemento Portland al mortero de cemento natural, también denominado cemento romano, cemento rápido o incluso cemento-yeso. El cemento natural, descubierto en 1796 por James Parker a partir de la cocción a unos $1.000^{\circ} \mathrm{C}$ de margas o calizas arciIlosas, fue muy apreciado durante el siglo XIX por su carácter hidráulico, rapidez de fraguado, resistencia, estética y durabilidad de las obras. Joseph Asdin (1778-1855) patentó en 1824 una versión artificial de este cemento mezclando componentes diversos y sometiéndolos a una cocción de $1.400^{\circ} \mathrm{C}$ para obtener un silicato tricálcico que denominó cemento Portland, por su similitud con la famosa piedra Portland de Inglaterra. En cualquier caso, el cemento Portland propiamente dicho no se fabricó de manera consistente hasta la década de $1850 .{ }^{117}$ Rafael Guastavino no apreciaba el cemento romano de antaño por su falta de homogeneidad que dependía de la calidad de la veta natural de piedra extraída y prefería el cemento Portland que ofrecía mayores garantías y uniformidad. ${ }^{118}$

En sus primeras obras empleó cemento natural semi-rápido de Gerona, ${ }^{119}$ no solo para doblar las bóvedas tabicadas, sino también eventualmente para fabricar en moldes las decoraciones de sus edificios, como en la Casa Víctor Blajot (18711872), ${ }^{120}$ antaño un uso completamente pionero en nuestro país. Sin embargo, apenas tuvo ocasión, en la erección de su propia casa en 1872, donde ejerció tanto de arquitecto como de constructor, importó cemento Portland desde Inglaterra. ${ }^{121}$ Si se considera que el cemento Portland fue importado a Estados Unidos desde Inglaterra solo en 1868 por primera vez, se entiende la trascendencia y carácter pionero de esta operación, además del grado de información que poseía Ra-

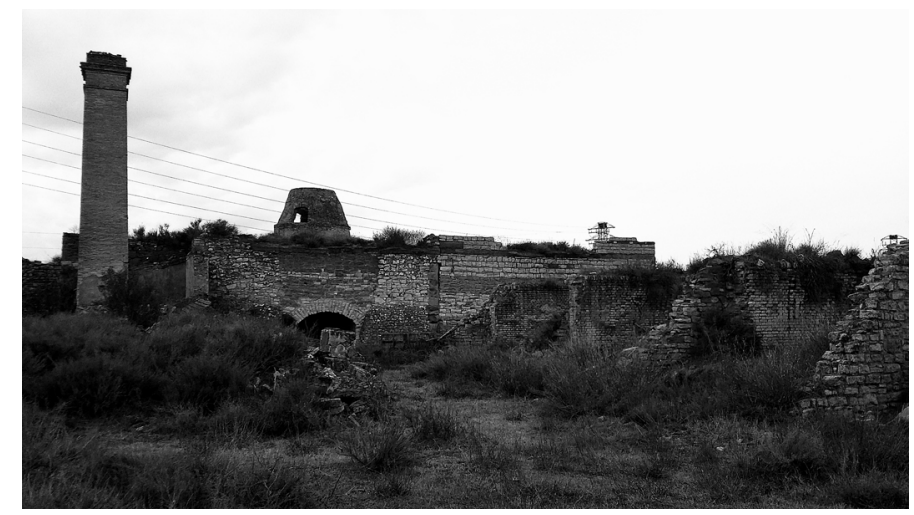

Fig. 5. Estado actual de la antigua fábrica de Rafael Montestruc en Tardienta (Huesca). Foto: Víctor M. Cantero.

fael Guastavino. En cualquier caso, no solo la importación de cemento desde Inglaterra era sin duda cara por los portes, sino que fue objeto de aranceles especiales para proteger la producción nacional de cemento romano. ${ }^{122}$ Ante estas dificultades, Rafael Guastavino tuvo que encontrar, educar y modelar a su antojo un productor que le suministrara un cemento de su confianza.

En inmediata cercanía de la Colonia de San Ginés (Huesca), donde Rafael Guastavino invirtió desde 1872 en adelante, se encuentra Tardienta, un municipio caracterizado por su suelo gipsífero y su explotación del yeso para la arquitectura tradicional, donde el industrial republicano Rafael Montestruc Mored (1826-1891), poseía una fábrica de yeso $^{123}$ (Fig. 5) y cemento romano, ${ }^{124}$ al menos desde 1867. Fue uno de los primeros productores de cemento natural en España. ${ }^{125}$ La fábrica se alza todavía a los pies de la estación de ferrocarril de Tardienta, seguramente, para facilitar el transporte de los productos realizados.

\footnotetext{
117 SKEMPTON, A.W. 1962, pp. 117-52.

118 GUASTAVINO MORENO, Rafael, 1895, pp. 11-12.
}

119 La noticia es de WIGHT, Peter B. "The Works of Rafael Guastavino. Part I-As Architect", The Brickbuilder, April, 1901 , p. 79. No se ha podido localizar la productora de cemento natural en Gerona en la década de 1860. Dadas las inexactitudes ocasionales del texto de Wight, por ejemplo, respecto a la figura de José Nadal -MILETO, Camilla; VEGAS, Fernando, 2012-, es también posible que la noticia se refiera al cemento de las Minas de la Granja de Escarpe del Bajo Segre (Lleida) del empresario Ignacio Girona y Agrafel (1824-1889), aunque su explotación oficial no comenzó de manera sistemática hasta 1876.

120 WIGHT, Peter B. "The Works of Rafael Guastavino. Part I-As Architect". The Brickbuilder, April, 1901, p. 81.

121 WIGHT, Peter B. "The Works of Rafael Guastavino. Part I-As Architect". The Brickbuilder, April, 1901, p. 79.

122 Diario de Huesca, 16 de marzo de 1878. La solicitud de imposición de aranceles especiales vino de parte de La Unión Minera, de Barcelona, en la que participaba también la familia Girona nombrada en la nota 103.

123 El Pirineo Aragonés, n. 1.524, 25-05-1912; El Pirineo Aragonés, n. 1.530, 27-07-1912; Publicidad, La Unión, n. 367, 08-011914. También registrada en el Anuario Almanaque del Comercio... Bailly-Bailliere, de los años 1879 y ss.

124 "Exposición Universal de 1867. Extracto del catálogo de España correspondiente a Obras Públicas". Revista de Obras Públicas, Tomo I, 16-05-1867, p. 195.

125 Editorial: "Ferrocarril central de Aragón". Gaceta de los Caminos de Hierro. Revista llustrada, 10-07-1896, p. 203. 
Rafael Montestruc Mored se licenció en Filosofía y Letras en la Universidad Sertoriana de Huesca y en Medicina por la de Barcelona. ${ }^{126}$ Poseía marcado carácter republicano y se relacionaba con intelectuales y personalidades políticas de gran influencia. No dudó en apoyar toda clase revoluciones habidas y por haber entre 1856 y 1868, cuando decidió fundar el periódico La Revolución. Precisamente este diario acogió a colaboradores como el mismo Emilio Castelar (1832-1899) o Estanislao Figueras (1819-1882). ${ }^{127}$ Fue militante y vicepresidente de la Junta Revolucionaria de Huesca donde coincidió con Antonio Torres-Solanot y Casas ${ }^{128}$ (18401902) en aquel momento su secretario. El primero de enero de 1869 fue nombrado alcalde primero de Huesca siendo su segundo Manuel Camo ${ }^{129}$ (1841-1911), a su vez militante del Partido Republicano Posibilista cuya primera figura era Castelar. Su hijo Luis Montestruc Rubio (1868-1897) le tomó el relevo aunque por poco tiempo, pues murió joven. Por mediación de Calixto Ariño (¿1831?-1897), a los 15 años entró en el periódico Diario de Avisos y dirigió además en 1888 La llustración aragonesa. Pronto acabaría fundando sus propios diarios, tales como La República (1894) y El Heraldo de Aragón (1895). Otro hijo de Rafael Montestruc, Joaquín, compartía ideales y amistad con Manuel Bes- cós (1866-1928) y con el intelectual Joaquín Costa (1846-1911), que era también amigo antiguo de su padre Rafael Montestruc. ${ }^{130}$

Guastavino se puso en contacto con Rafael Montestruc y le regaló el libro Recherches Expérimentales sur les Chaux de Construction, les Betons et les Mortiers ordinaires ${ }^{131}$ de Louis Joseph Vicat (1786-1861), referente internacional para la producción de cemento en el siglo XIX, donde se brindan explicaciones sobre la química del cemento, la cocción y el tipo de hornos. Con la ayuda del libro de Vicat, Rafael Montestruc consiguió fabricar un cemento Portland de bastante calidad ${ }^{132}$ y dejar atrás la producción de cemento romano. La propaganda de la empresa es buena muestra de la evolución de la empresa, que pasa de anunciar la venta de yeso de Tardienta -casi una denominación de origen- y cemento romano en $1867,{ }^{133}$ a diversificar específicamente la oferta de sus productos y publicitar la venta de cemento, cal hidráulica, cal natural y yeso en los años subsiguientes, $^{134}$ tras haber asimilado las enseñanzas de Vicat. Rafael Guastavino empleó su cemento a partir de entonces para sus obras. ${ }^{135}$ Consta además específicamente la utilización del cemento Montestru (sic) para la construcción del Teatro La Massa en Vilassar de Dalt (Barcelona). ${ }^{136}$

\footnotetext{
126 LÓPEZ, J. Manuel, 1992, p. 243. Con tan solo 15 años ingresó en el Colegio de Medicina y Cirujía de Barcelona.

127 D'ORIO, Bizén. "Historia de la prensa aragonesa". Diario de Aragón, 05-VI-2005, p. 75.
}

${ }^{128}$ Antonio Torres-Solanot fundó y dirigió en Zaragoza el periódico titulado El Progreso Espiritista. Dirigió también El Movimiento, diario democrático defensor de los ideales de Manuel Ruiz Zorrilla (1833-1895) y el periódico oscense El Alto Aragón en 1856. GIL NOGALES, Alberto, 1980.

129 GARCÉS MANAU, Carlos, 2012, p. 190

${ }^{130}$ En su estancia en Huesca como criado de su lejano pariente el maestro de obras Hilarión Rubio, Joaquín Costa ya había coincidido con Joaquín Montestruc porque residían curiosamente en el mismo edificio. Las relaciones entre Hilarión Rubio, acérrimo católico tradicionalista que acusaba a Joaquín Costa de racionalista y ateo, y Joaquín Montestruc, agnóstico y republicano militante, no debieron de ser muy fluidas. Existen numerosas citas y correspondencia que demuestran esta amistad entre los Montestruc y Joaquín Costa. Véase por ejemplo esta carta de Bescós a Costa, donde menciona a Joaquín como médico y fabricante de cemento en Tardienta en CHEYNE, G.J.G., 1979, p. 85.

131 WIGHT, Peter B. "The Works of Rafael Guastavino. Part I-As Architect". The Brickbuilder, April, 1901, p. 80.

132 Una vez más, la referencia de Wight es confusa, quizás debido a su desconocimiento de la química del cemento. La expresión literal de Wight es: "During his dealings with Dr. Montestru he gave the doctor Vicat's book on cement manufacture, with the help of which he succeeded in making a free silicate, or Portland cement of fair quality" (WIGHT, Peter B. "The Works of Rafael Guastavino. Part I-As Architect". The Brickbuilder, April, 1901, p. 80). La expresión "free silicate" no tendría mucho que ver con el cemento Portland, a no ser que quisiera indicar que todo el sílice habría reaccionado con el calcio para formar los silicatos de calcio característicos del cemento Portland, esto es, habría fabricado un cemento sin sílice libre vitrificada por haber reaccionado ésta toda con el calcio. La sílice libre vitrificada se habría comportado como árido, debilitando la mezcla. La clave estribaba probablemente en la proporción adecuada de arcilla (aprox. 25\%) en la marga calcárea a cocer, y en la temperatura de cocción, que debía pasar de los 1.000 grados característicos del cemento romano a los 1.450 grados del cemento Portland.

133 "Exposición Universal de 1867. Extracto del catálogo de España correspondiente a Obras Públicas". Revista de Obras Públicas, Tomo I, 16-05-1867, p. 195.

134 Véanse el Diario de Huesca, 12 de agosto de 1879; Diario de Huesca, 27 de mayo de 1882; Diario de Huesca, 30 de mayo de 1882.

135 WIGHT, Peter B. "The Works of Rafael Guastavino. Part I-As Architect", The Brickbuilder, April, 1901, p. 79.

136 ROSELL, Jaume, 1995, reeditado en: HUERTA, Santiago (ed.), 2001, p. 203. 
En búsqueda no solo de nuevos mercados para su arquitectura y su sistema constructivo de bóveda tabicada, sino también de un cemento Portland de calidad y garantías suficientes, ${ }^{137}$ Rafael Guastavino emigró, como ya se ha dicho, a Estados Unidos en 1881. Sin embargo, se equivocaba respecto al cemento puesto que, aun existiendo una incipiente producción de cemento Portland, era una industria que todavía se encontraba en sus inicios. Por el contrario, en la ciudad de Nueva York y gran parte de la Costa Este, el cemento más común empleado durante todo el siglo XIX fue el cemento natural Rosendale, un cemento de fraguado rápido producido en Rosendale (Estado de Nueva York) a partir de una caliza arcillosa. El porcentaje natural de magnesio y arcilla de esta caliza no requería su mezcla o combinación con otros materiales como sucedía frecuentemente con el cemento Portland. Este cemento natural local predominaba frente al cemento Portland importado o producido localmente en hornos tradicionales. El puente de Brooklyn, la Estatua de la Libertad y la mayor parte de los edificios de Manhattan del siglo XIX están construidos con este cemento, ${ }^{138}$ que sólo dejó de ser popular después de la Primera Guerra Mundial en beneficio del cemento Portland, probablemente por la mayor cantidad de mano de obra necesaria para preparar pequeñas cantidades de mezcla, al tener un fraguado demasiado rápido. ${ }^{139}$

El primer cemento Portland fabricado en Estados Unidos se produjo en una fábrica de David O. Seylor (1827-1884) en Coplay (Pennsylvania) en 1875 que, al igual que Rafael Guastavino, ${ }^{140}$ recibió una medalla en la Exposición del Centenario de Philadelphia un año después, en $1876 .{ }^{141}$ El listado de premiados en el catálogo de la Exposición de Philadelphia que Guastavino a buen seguro tuvo en sus manos por haber sido premiado también es quizás la razón por la que, desde España, pensó en que la industria del cemento Portland estaba muy desarrollada en Estados Unidos.

Toda esta producción ${ }^{142}$ de cemento, tanto en España como en Estados Unidos, tenía lugar en hornos cilíndricos de carga discontinua, un formato todavía derivado de los hornos tradicionales de cal o de yeso, ilustrados por Louis Vicat en su famoso libro. La patente de 1885 para un horno rotatorio de cemento del inglés Frederick Ransome (1818-1893) vino a modificar completamente la producción de cemento. José Francisco de Navarro (1823-1909), español residente en Estados Unidos, compró la patente de Ransome y creó la Keystone Portland Cement Co. en 1889, empleó con éxito desde el primer momento aceite como carburante en vez de gas y consiguió perfeccionar su tecnología en 1895 usando carbón pulverizado como combustible, entre otras mejoras, transformando ese mismo año la fábrica de cemento Keystone Portland Cement Co. en la Atlas Portland Cement Co. ${ }^{143}$

José Francisco de Navarro Arzac, ${ }^{144}$ industrial, financiero, constructor, armador, inventor, emigró desde Guipúzcoa a Cuba en 1838, donde comenzó a amasar su fortuna, y posteriormente a los Estados Unidos en 1855, donde llegaría a convertirse en uno de los hombres más ricos del país. José Francisco de Navarro poseía un extraordinario olfato para los negocios, asociándose con otros famosos armadores como Cornelius Vanderbilt (1794-1877) para la creación de su compañía na-

\footnotetext{
137 WIGHT, Peter B. "The Works of Rafael Guastavino. Part II-What is cohesive construction". The Brickbuilder, May, 1901, p. 101.

138 https://en.wikipedia.org/wiki/Rosendale_cement. (Fecha de consulta: 01-IV-2017).

139 WERNER, Dietrich; BURMEISTER, Kurtis. "An Overview of the History and Economic Geology of the Natural Cement Industry at Rosendale, Ulster County, New York". Journal of ASTM International, 2007, 4 (6). doi:10.1520/JAI100672. En este artículo se indica que se abandonó el uso del cemento romano tras la Primera Guerra Mundial "por su mayor tiempo de curado", un comentario que resulta de lo más extraño e incluso absurdo considerando que un cemento natural no debería necesitar curado.

140 VEGAS, Fernando, 2001, p. 257.

141 MEADE, Richard Kidder, 1906, pp. 4-14

142 Al parecer, durante su primera y gran promoción inmobiliaria, un bloque de apartamentos al pie de Central Park denominado Navarro Appartments o the Spanish Flats (1882), Navarro empleó tanto el cemento Rosendale como el cemento Portland y, viendo las ventajas de este último, decidió volcarse en su fabricación y mejora del proceso. Véase DOUET, James. "The Turnkey Factory: Technology Transfer from America to Spain in the Portland Cement Industry". Industrial Archaeology, Vol. $33, n^{\circ} .1,2007$, p. 28.

143 DOUET, James, 2007, pp. 27-37.

144 Para ahondar en esta figura bastante desconocida, véase: BURMAN, C. \& BEERMAN, E., 1998.
} 


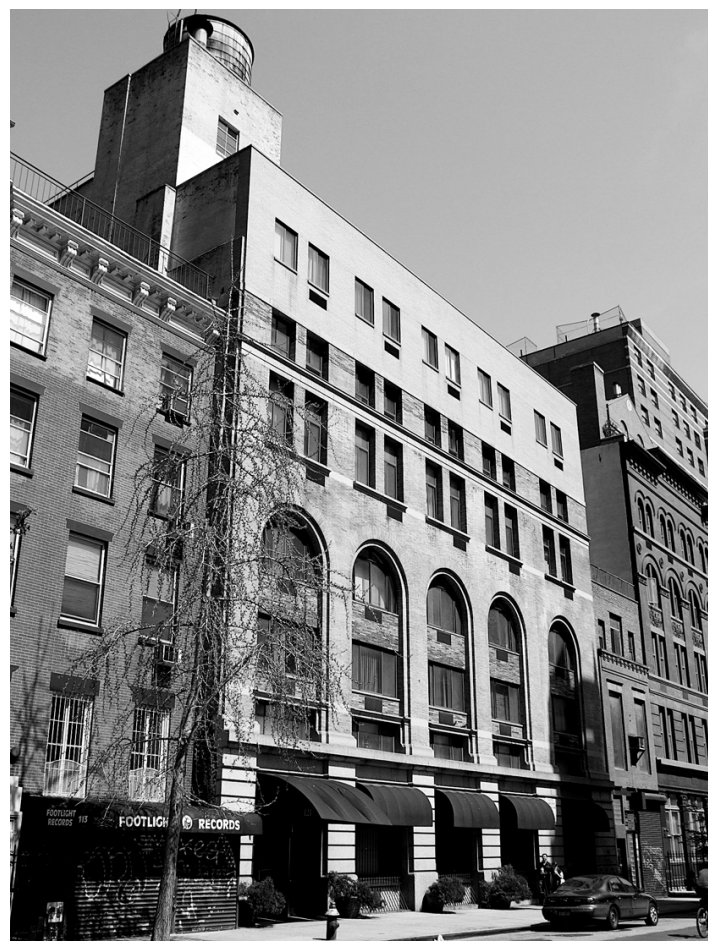

Fig. 6. Edificio de la Edison Electric Co. en 115 East 12 Street (1906), donde T.A. Edison recurrió a las bóvedas de Rafael Guastavino como sistema de construcción ignífugo. Foto: Vegas \& Mileto.

viera, con nada menos que George Pullman (18311897) para la creación del Metropolitan Elevated Railway de Nueva York, o incluso con el inventor Thomas Alva Edison (1847-1931) para la creación del Edison Electric Co.

Navarro junto a Edison, que también desarrolló mejoras al horno rotatorio en su empresa Edison Portland Cement Works de New Village (New Jersey), ${ }^{145}$ se fusionaron en la fábrica de cemento Universal Atlas Portland Cement Co. en 1902. Po- co después, Navarro se adjudicó el suministro de cemento para la construcción del Canal de Panamá. ${ }^{146}$ En 1904, Navarro ya era el mayor productor de cemento del mundo, con 8 millones de barriles al año. ${ }^{147}$

José Francisco de Navarro conocía a Rafael Guastavino. De hecho, Guastavino construyó el edificio Edison Electric Illuminating Co. (1893) en la First Avenue de Nueva York, en sustitución a la pionera Central Eléctrica Edison en Pearl Street (1882), malograda por un incendio, gracias a la intervención de José Francisco de Navarro. ${ }^{148}$ Además del patriotismo del que siempre hizo gala Navarro, que nunca llegó a nacionalizarse estadounidense en los más de cincuenta años que residió en el país, el sistema constructivo antiincendios de Guastavino a base de bóvedas tabicadas parecía el más adecuado para evitar futuros desastres. ${ }^{149}$ Posteriormente Guastavino construiría al menos dos edificios similares más para la compañía eléctrica de Edison en 39 Jane Street (1899) y en 115 East 12 Street (1906) (Fig. 6), ambos en igualmente en Manhattan. ${ }^{150}$

Es plausible que Navarro haya presentado o recomendado también a Guastavino a otros clientes, como la familia Vanderbilt (1862-1914), para quien construiría bóvedas trámite otros arquitectos al menos en la Hacienda Biltmore (1889-1896) en Asheville (Carolina del Norte), durante cuya obra decidió comprar unos terrenos en la cercana Black Mountain y erigir su rancho de retiro allí. Y posteriormente, en The Breakers en New Port, Rhode Island (1895), y en la Residencia Vanderbilt (1906), los apartamentos Vanderbilt (1910) y el Hotel Vanderbilt (1912), todos ellos en Manhattan. ${ }^{151}$ Además, el contacto tanto con Navarro como con Edison también puede haber servido de fuente de inspiración para el obsesivo registro de patentes de construcción con bóveda tabicada por parte de

145 Edison, T.A. 1904. Rotary Cement Kiln. US Patent 775600, 22 julio de 1903, concedida el 22 de noviembre de 1904.

146 GIRALT, Angela, 2001, p. xvii.

147 HABASHI, Fathi, 2010, pp. 57-60.

148 OCHSENDORF, John Allen, 2014, p. 65, nota 46; BURMAN, C. \& BEERMAN, E., 1998, pp. 172-175.

149 Se ha especulado sin fundamento hasta fecha de hoy con la posibilidad de que Rafael Guastavino hubiera emigrado a Estados Unidos para la construcción de la Central Eléctrica Edison en Pearl Street en 1882, construida con forjados de revoltones y (aparentemente) viguetas metálicas (no exactamente el sistema Guastavino al uso), que debían soportar seis dinamos de 27 toneladas cada una, a instancias del español José Francisco de Navarro, que tenía sus contactos en España y podía conocer su trayectoria como constructor de bóvedas tabicadas para pesadas fábricas de hilaturas en Barcelona. Es raro que esto fuera así, puesto que su intervención habría dejado alguna traza, aunque el incendio que destruyó los forjados no podía haber sido peor propaganda para la empresa. DOUET, J., 2007, p. 30; http://ethw.org/w/index.php?title=Thread:Rafael_Guastavino,_cons tructor_of_the_Pearl_St_station_(1)\&lqt_method=thread_history.

150 Datos obtenidos del Guastavino Project Timeline. Vertical Access (with the collaboration of the UPV), 2012.

151 OCHSENDORF, John Allen, 2014, p. 79. 
Guastavino padre e hijo. Por ejemplo, José Francisco de Navarro ${ }^{152}$ había registrado en Estados Unidos en 1871 una patente para el perfeccionamiento de los contadores de agua ( $n^{\circ} 114.419$ ), y una en España en 1894 para las mejoras introducidas en un sistema de ferrocarril eléctrico, ${ }^{153}$ además de la patente por su horno rotario para la producción del cemento. ${ }^{154}$ Por su parte, el inventor Edison llegó a registrar durante su vida 1.093 patentes.

La guerra hispano-estadounidense de 1898 afectaría en cierto modo a ambos españoles residentes en Nueva York. José Francisco Navarro dirigió la Junta Patriótica Española, un grupo de presión prohispano con sede en varias ciudades importantes, que trataban de compensar la campaña de difamación iniciada por el magnate de la prensa amarilla William Randolph Hearst (18631951). ${ }^{155}$ Por esta u otra razón desconocida, los encargos de Rafael Guastavino calaron en número en los dos últimos años del siglo XIX. ${ }^{156}$ Además de haber comenzado a amasar su fortuna en
Cuba, Navarro poseía propiedades e intereses económicos en las Antillas Mayores, ya que había creado junto a Edison en 1882 la Edison Spanish Colonial Light Company para introducir, producir y distribuir la electricidad en Cuba y Puerto Rico. Tras la guerra, los negocios millonarios de Navarro no parecieron sufrir a pesar de su claro posicionamiento prohispano, mientras que Guastavino pareció deber recurrir al famoso arquitecto y reconocido crítico Peter Bonnett Wight (1838-1925) para que le escribiera un cuádruple artículo laudatorio por entregas en la famosa revista The Brickbuilder, ${ }^{157}$ en modo de reactivar sus encargos y, su hijo solicitó y obtuvo la nacionalización estadounidense. Rafael Guastavino padre había recibido la naturalización de forma oficial el 27 de agosto de 1896, ${ }^{158}$ y Rafael Guastavino hijo, fue ciudadano americano de pleno derecho ya entrado el siglo XX, concretamente el 12 de octubre de $1900 .^{159}$

Al hilo de la posguerra, surgiría una ulterior ocasión de encuentro y colaboración entre Rafael Guastavino y José Francisco de Navarro en torno a

152 BURMAN, Conchita. "José Francisco Navarro. The Richest Spaniard in de USA". Guidepost, July, 1995, Vol. XXXVII, nº 20. Fuente: extraída de www.menbiografias.com

153 United States Patent Office, Letter Patent n 114.419; y Archivo Histórico de la Oficina Española de Patentes y Marcas, patente número 15.706. Fuente: extraída de www.menbiografias.com

154 Véase además de las notas anteriores: http://www.cementkilns.co.uk/early_rotary_kilns.html

155 MOA, Pío, 2004, p. 75.

156 Datos obtenidos del Guastavino Project Timeline. Vertical Access (with the collaboration of the UPV), 2012.

${ }^{157}$ WIGHT, Peter B. "The Works of Rafael Guastavino. Parts I, II, III, IV". The Brickbuilder, April, May, September, October 1901.

158 https://familysearch.org/ark:/61903/1:1:VXR7-WJF. № de Microfilm: 1429741, imagen 529 (Fecha de consulta: 19-IV-2012).

159 https://familysearch.org/ark:/61903/1:1:VXR7-WJN. Nº de Microfilm: 1429741, imagen 530 (Fecha de consulta: 19-IV-2012). La naturalización parece que vino aparejada con la solicitud de pasaporte para viajar fuera de Estados Unidos. El pasaporte de Rafael Guastavino Expósito fechado en 1904 reza: "I solemny swear that was born at Barcelona Spain, on or about the 12 day of May 1872; that I emigrated to the United States, sailing on board the Marseilles from Havre on or about the 15 day of march 1881...". (En: https://familysearch.org/ark:/61903/1:1:Q295-VQFK. № de Microfilm 001521384. Fecha de consulta: 24-II2015). Los autores han podido comprobar según afirma el hijo del arquitecto, que efectivamente partieron desde el Puerto de Le Havre en la Normandía el 15 de marzo de 1881, y no desde el de Marsella, como inicialmente se había afirmado en la bibliografía. El barco se llamaba Ville de Marseilles, y esto podría explicar el error que se ha venido acumulando a lo largo del tiempo. Hemos podido obtener también la hoja de desembarco en el Puerto neoyorkino de Ellis Island el 2 de abril de 1881, en la que queda constancia del nombre de los pasajeros y procedencia de los mismos (https://familysearch.org/ark:/61903/1:1: QVSK-T343. № de Microfilm 1429741. Fecha de consulta: 21-I-2016). Gracias a este documento hemos podido poner nombre a las hijas de Paulina Roig, eran Francisca y Engracia Valls. Efectivamente Paulina estuvo casada con Juan José Valls Corral nacido en Barcelona hacia 1831 y de profesión pintor (ACB, Matrimonis, 1858, Registres, Llibre 304, fol. 311r, núm. 1233). No se ha podido determinar si Paulina enviudó o se separó del pintor Juan José Valls. En su viaje a Le Havre para coger el barco a Estados Unidos, es fácil que recalaran en París donde residía un primo hermano de Rafael Guastavino Moreno, llamado Climent Puyol i Guastavino, pintor de reconocido prestigio. Era hijo de Antonia Guastavino Buch, a su vez hija de David J. Guastavino y Antonia Buch Martínez. Climent Puyol i Guastavino nació en Olesa de Montserrat hacia 1850 y estudió en la escuela de Bellas Artes de Barcelona. Emigró a París en 1876 y en la ciudad del Sena fue discípulo de los pintores Louis Nicolas Cabat (1812-1893) y de Jean Leon Gérome (1824-1893). Participó desde 1876 en el Salón de París y en otros muchos certámenes de calado internacional con numerosas obras y estableció su taller en Rue Boissonade, 11. Véase: FLAQUER i REVAUD, Silvia; PAGÉS i GILIBETS, Ma Teresa. Inventari d'artistes catalans que participaren als Salons de París fins l'any 1914. Barcelona: Diputació de Barcelona, 1986; y http://wm1640482.web-maker.es/BIOGRAF-AS-DE-PINTORES-A/Climent-Pujol-de-Guastavino (Fecha de consulta: 31-I-2017). Su madre Antonia Guastavino Buch falleció en Barcelona el 22 de abril de 1874 a los 55 años en su casa de la calle Milans $n^{\circ} 2$ ( $A C B$, Defuncions, Registres, 1874, Llibre 2, fol. s/n, $n^{\circ} 3130$ ). Es fácil que fuera un familiar de referencia también para Juana Guastavino Moreno, hermana del arquitecto, que vivió en París durante unos años antes de partir a Nueva York en 1908 desde el puerto de Cherbourg, muy cercano al mencionado anteriormente de Le Havre. 
la producción de cemento que tanto interés personal había despertado en ambos personajes. Es muy probable que, además del empleo en sus inicios del cemento natural Rosendale, Rafael Guastavino empleara entre otros el propio cemento Portland de Navarro, de la empresa Universal Atlas. De la misma forma que Guastavino había transferido desde España a Estados Unidos la técnica tradicional de la bóveda tabicada mejorada con el empleo del mortero de cemento, ${ }^{160}$ ahora Navarro -con la colaboración de Guastavinotransferiría la última tecnología de producción de cemento que él en persona había contribuido a mejorar desde Estados Unidos a España. ${ }^{161}$ La guerra entre Estados Unidos y España estaba muy reciente, así que es de suponer que esta colaboración no fue en principio fácil.

Valiéndose de su amistad con Navarro, Rafael Guastavino propuso a Eusebi Güell la creación de una fábrica de cemento de Portland, con los nuevos hornos rotarios perfeccionados por el mismo Navarro. ${ }^{162}$ Con Güell había tenido probablemente contacto en Barcelona a través, entre otros motivos, de la Fundición La Maquinista Terrestre y Marítima propiedad de su padre que le suministraba columnas de fundición para sus obras. ${ }^{163}$ Además de invertir capital en la fábrica de cemento Atlas de Estados Unidos, Güell concibió una fábrica con seis hornos rotatorios en un lugar a los pies del Pirineo Catalán en un monte con vetas de piedra caliza adecuadas con un generoso salto de agua para proporcionar energía. El enclave se llama el Clot del Moro y está ubicado en el municipio de Castellar de N'Hug (Barcelona). El clima es tan frío que Güell decidió amparar todo el proceso de fabricación bajo una estructura arquitectónica, una actitud inusual en este tipo de fábricas. La nueva fábrica denominada Compañía General de Asfaltos y Portland o simplemente Asland, se fundó en 1901. Tanto el proyecto de la fábrica como toda la maquinaria se encargó a la Compañía Allis-Chalmers de Milwaukee (Wisconsin), y los planos para las construcciones al arquitecto Rafael Guastavino. ${ }^{164}$ El conjunto, que se concibió y contrató como fábrica de llaves en mano, requirió la presencia de ocho ingenieros y cinco técnicos auxiliares provenientes de Milwaukee, Nueva York y California, entre los que destaca William Wallace Ewing (1866-1928), un ingeniero que había trabajado en el pasado con Guastavino, cuya firma aparece en casi todos los planos. La obra, un impresionante conjunto encabalgado de bóvedas tabicadas sobre cerchas metálicas, fue supervisada por el joven arquitecto Isidoro Pedraza de la Pasqua, español que residía en Nueva York y que, previamente asesorado por Guastavino, retornó hasta Barcelona a tal fin. ${ }^{165}$

\section{Coda final}

Con esta fábrica de cemento, se cerraba así un círculo de relaciones biunívocas entre ambos continentes que había comenzado al menos veinte años antes, cuando Rafael Guastavino, con todo el bagaje arquitectónico heredado de su tatarabuelo perfeccionado con su inquietud por los nuevos materiales, con su espíritu emprendedor que le llevó a la creación pionera de una explotación vitivinícola, con sus rudimentos de carpintería que apuntalaron su vocación de constructor, y con su sensibilidad musical rayana en la arquitectónica a sus espaldas, decidió hacer las Américas.

\section{Bibliografía}

ALEMANY, Victoria. "La construcción de pianos en Valencia hasta inicios del siglo XX". Anuario musical, $\mathrm{n}^{\circ}$ 62, 2007, pp. 335-364.

ALVIRA BANZO, Julio. "Contenson y Oliver, dos pioneros en la mecanización agraria oscense". Diario del Alto Aragón, 10-VIII-2009.

ASENJO BARBIERI, Francisco. Documentos sobre música española y epistolario (Legado Barbieri), vol. 2, Ed. de Emilio Casares. Madrid: Fundación Banco Exterior, 1988.

BRUGAROLAS, Oriol. El piano en Barcelona (1790-1849): construcción, difusión y comercio. Universitat de Barcelona, 2015.

\footnotetext{
160 COLLINS, George, 1968, pp. 176-201.

161 DOUET, James, 2007, pp. 27-37.

162 El Financiero, Años XXIV, Octubre de 1924, p. 196.

${ }^{163}$ Carta de pago firmada en 1870 por la empresa y los Hermanos Batlló (AHPB, 1312/57: Ferran Ferran Sobregues, ápoca de las sociedades "La Maquinista" e "Ignacio y Casimirio Girona", núm. 161, ff. 576-581, 11/05/1870), citada por LUENGO PÉREZ, Noelia; VEGAS, Fernando; MILETO, Camila, 2016, pp. 393-402.

164 El Financiero, Años XXIV, Octubre de 1924, p. 196. Véase también: TARRAGÓ, Salvador, 2002, pp. 12-15.

165 TARRAGÓ, Salvador, 2002, p. 15.
} 
BULMBERG, Edgardo. "Carlos Guastavino". Proyecto Aula-Ciudad, 2008.

BURMAN, Conchita. "José Francisco Navarro. The Richest Spaniard in de USA". Guidepost, July, 1995, vol. XXXVII, $n^{\circ} 20$.

BURMAN, C. \& BEERMAN, E. Un vasco en América: José Francisco Navarro Arzac (1823-1909). Madrid: Eurolex, 1998.

CHEYNE, G.J.G. Confidencias políticas y personales: Epistolario J. Costa-M. Bescós 1899-1910. Zaragoza: Institución Fernando el Católico, 1979.

COLLINS, George. "The transfer of thin masonry vaulting from Spain to America". Journal of the Society of architectural Historians, vol. 27, No. 3, Oct., 1968, pp. 176-201, doi: 10.2307/988501.

CONRADO, Ángel. Religiosos ilustres de las seráficas provincias de valencia. Valencia: Editorial Revista Apóstol y Civilizador, 1988.

DOUET, James. "The Turnkey Factory: Technology Transfer from America to Spain in the Portland Cement Industry". Industrial Archaeology, Vol. 33, n. 1, 2007.

FLAQUER i REVAUD, Sílvia; PAGÉS i GILIBETS, Mª Teresa. Inventari d'artistes catalans que participaren als Salons de París fins I'any 1914. Barcelona: Diputació de Barcelona, 1986.

FLEITAS, Ma Teresa. "Santiago de Cuba: la modernización postergada". En: Estudios de historia social y económica de América, $\mathrm{n}^{\circ} 12,1995$, pp. 141-164.

GARCÉS MANAU, Carlos. El Ayuntamiento de Huesca: Historia, Arte y Poder. Huesca: Instituto de Estudios Altoaragoneses, 2012.

GIL NOGALES, Alberto. La revolución de 1868 en el Alto Aragón. Zaragoza: Ed. Guara, 1980.

GIRALT, Ángela. "Prólogo" en HUERTA, Santiago (ed.). Las bóvedas de Guastavino en América, Madrid: Instituto Juan de Herrera, 2001.

GUASTAVINO IV, R. An Architect and his Son. Maryland: Heritage Books, 2006.

GUASTAVINO MORENO, Rafael. Prolegómenos á las Funciones de la Mampostería en las Modernas Construcciones Arquitectónicas, texto en castellano sin fecha (prólogo firmado en New York, Noviembre 1895), B.N.E. Sede Recoletos $1 / 9289$, Código de barras 1103203488; Sede Alcalá DGMICRO/30749. Código de barras 3974888-2001.

HABASHI, Fathi. "History of the rotary kiln". En: De Re Metallica, 15, 2010.

HERNÁNDEZ Balaguer, Pablo. "La capilla de música de la Catedral de Santiago de Cuba". En: Revista musical chilena. Santiago de Chile, 1964, pp. 14-61.

HUERTA, Santiago (ed.). Las bóvedas de Guastavino en América. Madrid: Instituto Juan de Herrera, 2001.

LÓPEZ GÓMEZ, J. Manuel. "La matrícula de médico-cirujanos del Real Colegio de Medicina y Cirugía de Barcelona de 1828 a 1842". En: Gimbernat, XVIII, 1992, pp. 217-256.

LOREN MÉNDEZ, M. Mar. "La obra de la compañía Guastavino en Nueva York. Su actualidad y restauración". Loggia, Arquitectura \& Restauración, n²0, 2007.

LOREN MÉNDEZ, M. Mar. Texturas y Pliegues de una nación. New York City: Guastavino Co. y la reinvención del espacio público de la metrópolis. Valencia: TC Ediciones 2008.

LUENGO PÉREZ, Noelia. VEGAS LÓPEZ-MANZANARES, F.; MILETO, Camilla. "Rafael Guastavino, más allá de la bóveda tabicada". En: COLLADO ESPEJO, Pe- dro E. (ed.). Actas del Congreso Internacional EI Mo dernismo en el Arco Mediterráneo CIMAM 2016. Cartagena: Universidad Politécnica de Cartagena, 2016.

MARTíNEZ, Bizén. "Historia de la prensa aragonesa". Diario de Aragón, 05-VI-2005.

MARTÍNEZ MOLÉS, Vicente. Francisco Andreví Castellá y la música española del clasicismo. Universitat de Valencia, 2015.

MOA, Pío. Una historia chocante: los nacionalismos vasco y catalán en la historia contemporánea de España. Madrid: Ediciones Encuentro, 2004.

MUNTADAS, Juan Federico. El Monasterio de Piedra. Zaragoza: Torres \& Associats S.L. [1871], 2002.

OCHSENDORF, John Allen. Guastavino vaulting. The art of structural tile, Princeton Architectural Press 2014; publicado también en castellano: OCHSENDORF, John Allen. Las bóvedas de Guastavino: el arte de la rasilla estructural. Barcelona: Papersdoc, Ajuntament de Barcelona, 2014.

OLIVA i RICÓS, Benet. "L'etapa catalana de Rafael Guastavino (1859-1881)". XI Congrès d'Història de la Ciutat. La ciutat em xarxa. Ed. Archivo Histórico de la Ciudad de Barcelona, Instituto de Cultura. Barcelona: Ayuntamiento de Barcelona, 2009.

REDONDO MARTÍNEZ, Esther. "Las patentes de Guastavino \& Co. en Estados Unidos (1885-1939)". En: GRACIANI, A.; HUERTA, Santiago; RABASSA, Enrique \& TABALES, M. Actas del Tercer Congreso Nacional de Historia de la Construcción. Sevilla, 26-28 octubre 2000, Madrid: I. Juan de Herrera, SEdHC, U. Sevilla, Junta Andalucía, COAAT Granada, CEHOPU, 2000.

ROSELL COLOMINA, J. "Rafael Guastavino i Moreno: enginy en I'arquitectura del segle XIX". En: Ciència $i$ Tècnica als Països Catalans: una aproximació biogràfica. Barcelona: Fundación Catalana per la recerca, 1995.

SKEMPTON, A.W. "Portland Cements, 1843-1887". Transactions of the Newcomen Society, 1962.

TARRAGÓ, Salvador. Guastavino Co. (1885-1962). Catalogue of works in Catalonia and America. Barcelona: Col.legi d'Arquitectes de Catalunya, 2002.

VEGAS LÓPEZ-MANZANARES, Fernando. "Los orígenes valencianos en la obra de Guastavino". En: HUERTA, Santiago. Las bóvedas de Guastavino en América. Madrid: Instituto Juan de Herrera, 2001.

VEGAS LÓPEZ-MANZANARES, Fernando; MILETO, CamiIla. "Rafael Guastavino: una historia de la arquitectura entre bambalinas". Loggia, Arquitectura \& Restauración, $\mathrm{n}^{\circ} 20,2007$.

VEGAS LÓPEZ-MANZANARES, Fernando; MILETO, CamiIla. "Consistencia de las raíces valencianas en la obra de Guastavino". En: LOREN MÉNDEZ, M. Mar. Guastavino Co. La reinvenció de l'espai públic a New York. Valencia: Generalitat Valenciana, 2008.

VEGAS LÓPEZ-MANZANARES, Fernando; MILETO, CamiIla. "Guastavino y el eslabón perdido". En: Construyendo bóvedas tabicadas: actas del Simposio Internacional sobre bóvedas tabicadas (celebrado los días 26, 27 y 28 de mayo de 2011). Valencia: Editorial Universitat Politècnica de València, 2012.

WIGHT, Peter B. "The works of Rafael Guastavino. Part I: As architect". En: The Brickbuilder, Abril, 1901.

WIGHT, Peter B. "The life and Work of Rafael Guastavino. Part II: What is cohesive construction". En: The Brickbuilder, Mayo, 1901. 
WIGHT, Peter B. "The life and Work of Rafael Guastavino. Part III: The practice of architecture and cohesive construction in America". En: The Brickbuilder, Septiembre, 1901.

WIGHT, Peter B. "The life and Works of Rafael Guastavino. Part IV: The practice of architecture and cohesive construction in America". En: The Brickbuilder, Octubre, 1901.

\section{Agradecimientos}

Se agradece la colaboración en el estímulo, la búsqueda de archivos, la elaboración y la revisión de este artículo a las siguientes personas: Peter Austin, Rafael Catón, Teresa Corz, Berta de Miguel, Fabio Fratini, Ramon Graus, Nemesio A. Martínez Pérez, Javier Moro, Ana Oliva Mora, Benet Oliva i Ricós, Javier Olona, José Pont, José Ángel Viñuales. 